Article

\title{
Shipboard Data Compression Method for Sustainable Real-Time Maritime Communication in Remote Voyage Monitoring of Autonomous Ships ${ }^{\dagger}$
}

\author{
Irena Jurdana ${ }^{1}$, Nikola Lopac ${ }^{1,2, *} \mathbb{D}$, Nobukazu Wakabayashi ${ }^{3}$ and Hongze Liu ${ }^{3}$ \\ 1 Faculty of Maritime Studies, University of Rijeka, 51000 Rijeka, Croatia; jurdana@pfri.hr \\ 2 Center for Artificial Intelligence and Cybersecurity, University of Rijeka, 51000 Rijeka, Croatia \\ 3 Graduate School of Maritime Sciences, Kobe University, Kobe 658-0022, Japan; waka@kobe-u.ac.jp (N.W.); \\ i@liu.am (H.L.) \\ * Correspondence: lopac@pfri.hr \\ $+\quad$ This paper is an extended version of our paper published in Wakabayashi, N.; Jurdana, I. Maritime \\ Communications and Remote Voyage Monitoring. In Proceedings of the 2020 International Conference on \\ Broadband Communications for Next Generation Networks and Multimedia Applications (CoBCom), \\ Graz, Austria, 7-9 July 2020; pp. 1-8.
}

check for

updates

Citation: Jurdana, I.; Lopac, N.; Wakabayashi, N.; Liu, H. Shipboard Data Compression Method for Sustainable Real-Time Maritime Communication in Remote Voyage Monitoring of Autonomous Ships. Sustainability 2021, 13, 8264. https:// doi.org/10.3390/su13158264

Academic Editor:

Mohammad Valipour

Received: 29 June 2021

Accepted: 22 July 2021

Published: 23 July 2021

Publisher's Note: MDPI stays neutral with regard to jurisdictional claims in published maps and institutional affiliations.

Copyright: (c) 2021 by the authors. Licensee MDPI, Basel, Switzerland. This article is an open access article distributed under the terms and conditions of the Creative Commons Attribution (CC BY) license (https:// creativecommons.org/licenses/by/ $4.0 /)$.

\begin{abstract}
Due to the ever-increasing amount of data collected and the requirements for the rapid and reliable exchange of information across many interconnected communication devices, land-based communications networks are experiencing continuous progress and improvement of existing infrastructures. However, maritime communications are still characterized by slow communication speeds and limited communication capacity, despite a similar trend of increasing demand for information exchange. These limitations are particularly evident in digital data exchange, which is still limited to relatively slow and expensive narrowband satellite transmission. Furthermore, with the increasing digitalization of ships and introducing the sustainable concept of autonomous ship operation, large amounts of collected data need to be transmitted in real-time to enable remote voyage monitoring and control, putting additional pressure on the already strained means of maritime communications. In this paper, an adaptive shipboard data compression method based on differential binary encoding is proposed for real-time maritime data transmission. The proposed approach is verified on the actual data collected on board a training ship equipped with the latest data acquisition system. The obtained results show that the proposed data encoding method efficiently reduces the transmitted data size to an average of $3.4 \%$ of the original shipboard data, thus significantly reducing the required data transmission rate. Moreover, the proposed method outperforms several other tested competing methods for shipboard data encoding by up to $69.6 \%$ in terms of compression efficiency. Therefore, this study suggests that the proposed data compression approach can be a viable and efficient solution for transmitting large amounts of digital shipboard data in sustainable maritime real-time communications.
\end{abstract}

Keywords: maritime communications; data compression; encoding; remote voyage monitoring; autonomous ship; maritime transport

\section{Introduction}

Today's land-based communications systems are subject to constant improvements and upgrades of existing infrastructure due to the ever-increasing need for widely available, rapid, and stable exchange of large amounts of information in real time. On the other hand, despite efforts to improve [1-6], maritime communications systems still lag behind in this respect and are mainly characterized by low speeds, relatively high costs, and limited availability and capacity.

Recent trends in the maritime transport include the increasing digitalization of ships and related maritime services [7-9] and introducing the concept of autonomous ship 
operation [10-15]. The digital ship concept, illustrated in Figure 1, and the concept of autonomous ship operation imply the collection of large amounts of data from various measurement systems on board the ship [16], real-time digital data exchange, and the application of advanced information technologies for remote monitoring and control of the ship, automation of ship operation, and other advanced functions. These innovative concepts are expected to contribute to a more sustainable maritime transport, enabling energy savings and maritime environment protection $[17,18]$.

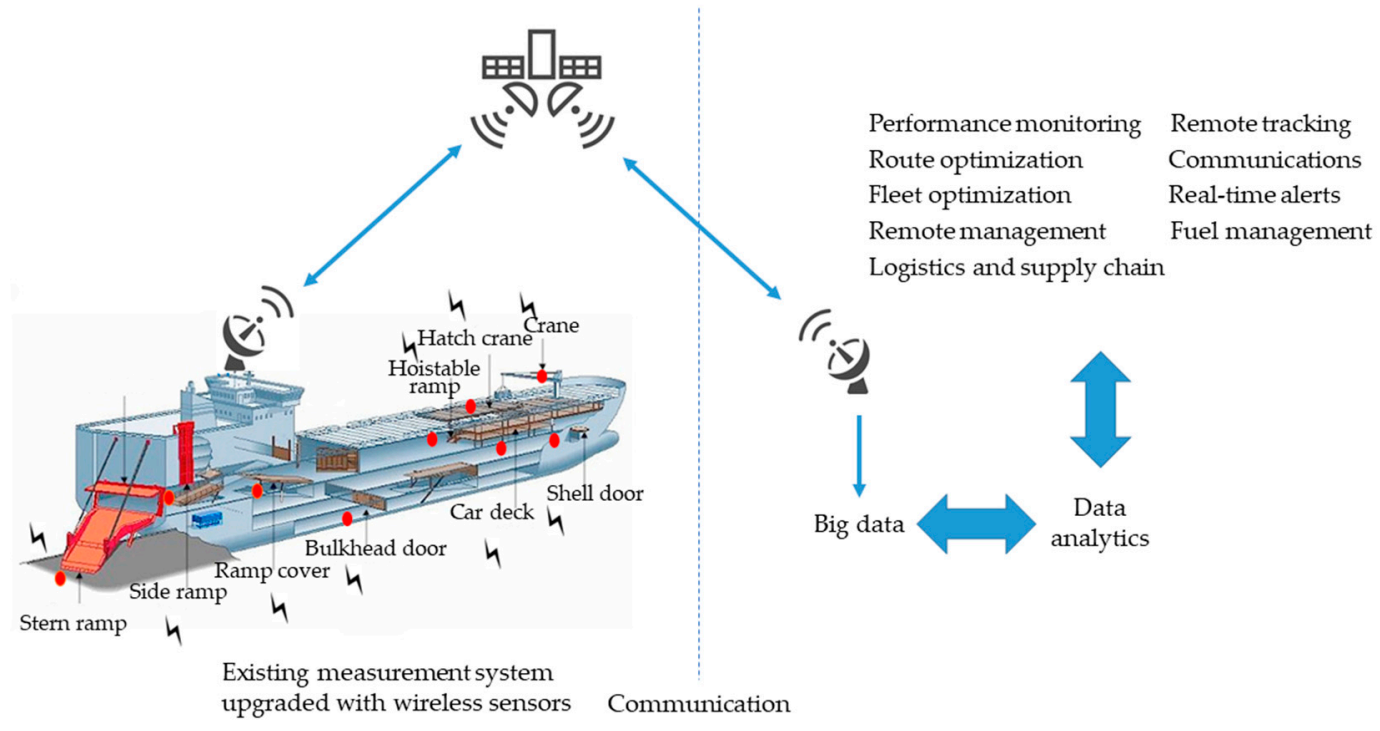

Figure 1. Digital ship concept.

However, unlike the widely used Automatic Identification System (AIS) [19-21], where a limited amount of predetermined data is transmitted to vessels and coast stations within the range, the digital ship and autonomous ship concepts require continuous realtime transmission of large amounts of digital data. Moreover, since these data are to be transmitted to the land-based stations and operators for further analysis and processing, satellite communications are used for this purpose instead of terrestrial systems. In addition, the need for high-speed and reliable Internet access for both ship's crew and passengers is rapidly increasing. Thus, the previously mentioned limitations of existing maritime communications systems may hinder adopting and implementing these novel concepts in the maritime industry. Therefore, upgrades and modernization of existing systems and construction of new systems will be necessary. However, modernization requires major interventions into the equipment and the investment of significant financial and material resources.

An alternative approach to relieving the load on maritime communications systems could be to reduce the size of the transmitted data by applying compression techniques based on specialized algorithms for shipboard data encoding [22,23]. These algorithms could be efficiently implemented in the ship communication system, thus avoiding extensive interventions and investments.

In this paper, a method for shipboard data compression based on variable-recordlength encoding is proposed. The proposed technique utilizes a six-bit differential binary encoding of the shipboard data collected by different systems and navigation devices. In order to verify the efficiency of the proposed method and test it under real-life conditions, we applied it to the actual data collected on board the training ship equipped with state-of-the-art electronic systems. The obtained results show that the proposed method significantly reduces the size of the initially transmitted data, thus reducing the required data transmission rate and the demands on the maritime communications systems. Moreover, the proposed encoding technique shows superior performance compared to several tested data encoding techniques of similar complexity. Therefore, the results presented in this 
paper indicate that the proposed straightforward data encoding method can be efficiently implemented in the ship communication system, thus enabling the future application of remote voyage monitoring of autonomous ships.

The rest of this paper is organized as follows. Section 2 gives a brief overview of maritime communications systems, emphasizing AIS and the corresponding data transmission protocol as an example of an existing application of data encoding technique in today's maritime communications. The conducted experimental shipboard data acquisition and the proposed data compression method are described in Section 3. Next, the obtained results are presented and discussed in Section 4. Finally, conclusions are summarized in Section 5.

\section{Maritime Communications Systems}

\subsection{Overview of Maritime Communications}

Wireless communication is the only viable solution for ships at sea to exchange information with other ships and land-based stations. Before the development of modern wireless communications systems, ship communication was limited to communication within a visible distance using signals with various lights and flags. Ships began to be equipped with wireless communication devices with the invention of radiotelegraphs. However, there were no system regulations for distress communications until 1914, when the first version of the International Convention for Safety of Life at Sea (SOLAS) was adopted in response to the RMS Titanic disaster [24].

Maritime communications have been used for three primary purposes: distress and safety communications, communications in support of navigation, and general communications. Distress and safety communications include distress calls and communication during search and rescue (SAR) operations for vessels in distress. In contrast, communications supporting navigation refer to exchanging information with nearby vessels and port managers during a voyage. Finally, general-purpose communications include various public communication services that serve similar purposes as on land.

Maritime communications have recently seen an increased transition from analog to digital communications, as well as a significant increase in the need to exchange larger amounts of data in general. With the implementation of the Global Maritime Distress and Safety System (GMDSS) [25-27] in 1999, it became possible to send digital distress signals automatically via satellite communications, instead of the already obsolete methods of sending SOS or Mayday messages via telegraph and telephone, respectively. Communications in support of navigation have also evolved with the introduction of digital radio communications systems, such as AIS [19], which allows the exchange of navigational information with nearby vessels and coast stations via terrestrial Very High Frequency (VHF) communications. General public communications include using various Internet services by ship's crew and passengers, which is achieved using maritime communications satellites.

The maritime communication system GMDSS is based on the requirements of the SOLAS Convention and the International Convention on Maritime Search and Rescue (SAR) [28]. The GMDSS enables the automatic transmission of digital distress signals in the form of digital selective calls (DSC). This form of low-speed digital communication replaced voice communication over the VHF band, which was mainly used for these purposes. Thus, the GMDSS removes the requirements for specific qualifications, such as the use of Morse code, in favor of the efficient utilization of simple distress buttons and switches. Therefore, any crew member can respond in the event of an emergency. In addition, the GMDSS relies on satellite communications to ensure stable communications and requires maintenance of radio equipment to ensure reliable operation while the vessel is underway. The overview of the GMDSS is shown in Figure 2. 


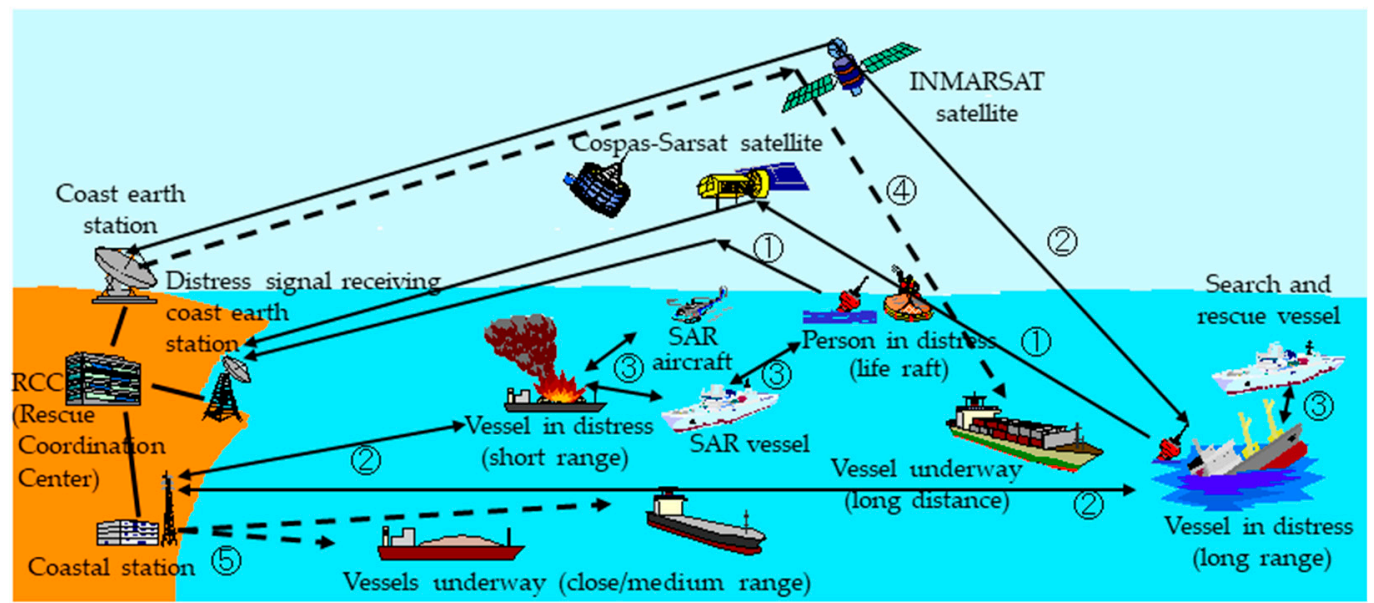

(1) Automatic transmission of distress signal (Satellite EPIRB, SAR/Galileo)

(2) Distress communication (DSC, MF/VHF transceiver, INMARSAT, NBDP)

(3) Search and rescue communication (two-way radio telephone, VHF)

(4) Safety information (INMARSATEGC)

(5) Safety information (NAVTEX)

Figure 2. Overview of the GMDSS.

With their activation in the second half of the twentieth century, communications satellites became widely used for long-distance maritime communications, which until then had been limited to the use of radio waves in the Medium Frequency/High Frequency (MF/HF) band. Today, mobile communications via Inmarsat satellites, among others, are used, offering different services, such as Fleet Xpress, FleetBroadband, and Inmarsat $C[29,30]$. In addition to the initially used voice communication, data transmission via satellite communications is becoming more and more developed. However, satellite communications still use a narrow band, which leads to a lower communication speed. In addition to the lower bandwidth, the fees for using satellite communication are still relatively high, so that this form of communication is not an optimal solution for transmitting larger volumes of maritime data over longer distances.

VHF Data Exchange System (VDES) is a maritime radio communication system that uses the Maritime mobile VHF band for relatively low-speed communication between ships, coast stations, and low Earth orbit (LEO) satellites [31]. VDES consists of the following components: AIS, Application Specific Messages (ASM), and VHF Data Exchange (VDE). AIS [19] enables digital communication between the ship and the receivers within the range, including those on other ships or coast stations. A regulation [32] effective since 2004 made AIS mandatory equipment for ships of 300 gross tonnage (GT) or more on international voyages, cargo ships of $500 \mathrm{GT}$ or more not in international waters, and all passenger ships [20]. As a technology that is the subject of many research studies and is being used in the development of various new applications [21,33-37], AIS is discussed in more detail in the following subsection.

\subsection{Automatic Identification System (AIS)}

AIS offers the $9.6 \mathrm{kbps}$ digital communication via VHF communication channels using Gaussian minimum shift keying (GMSK) modulation. The AIS-based communication is used to transmit digital voyage data collected on board the ship. In addition to transmitting relevant data, the ship's AIS transceiver can simultaneously receive data from nearby ships, allowing them to identify each other. The AIS transceivers use the $156 \mathrm{MHz}$ radio band, with an output power of up to $12.5 \mathrm{~W}$. Therefore, vessels and stations can receive the AIS signal within a range of $30-40 \mathrm{~km}$. Figure 3 shows the overview of maritime communication realized using AIS. The communication occurs between ships and between ships and land-based Vessel Traffic Service (VTS) stations. The data transmitted via AIS can 
be roughly divided into three main categories: dynamic information, static information, and voyage-related information.

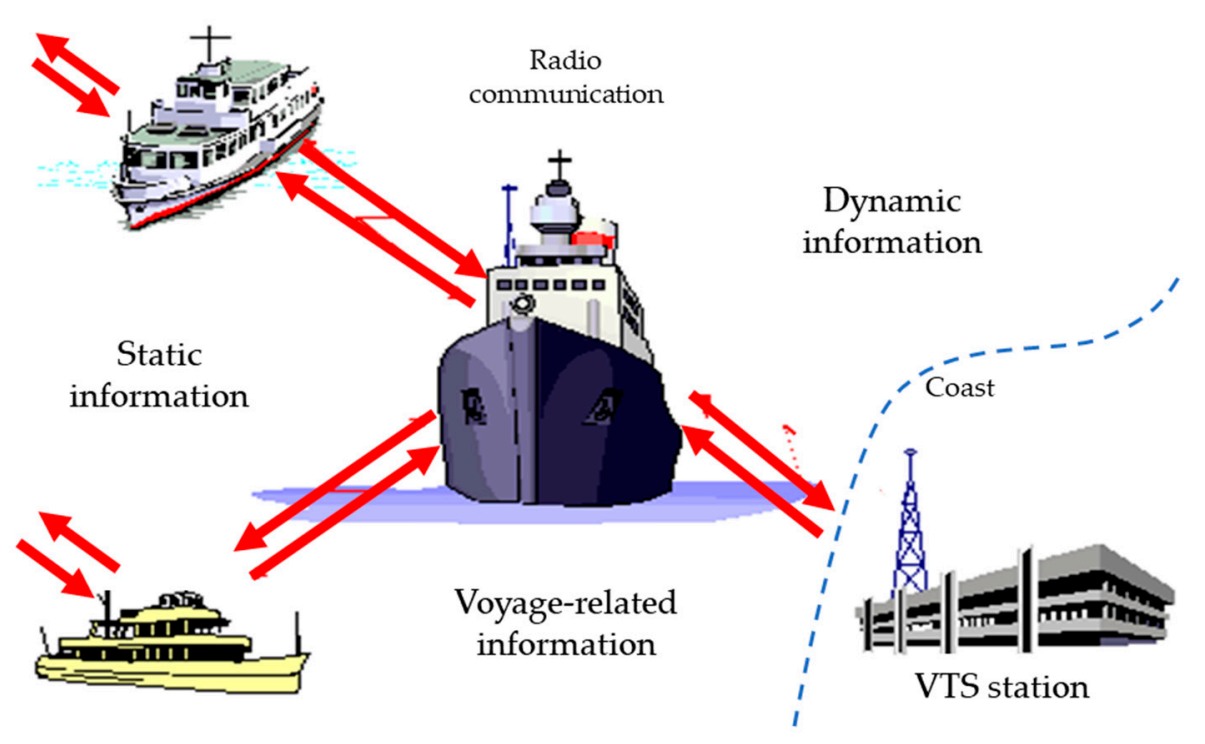

Figure 3. Overview of the AIS communication.

Dynamic information represents the ship's position report and is transmitted every $2-10 \mathrm{~s}$ depending on the ship's speed while the ship is underway or every $3 \mathrm{~min}$ when the ship is at anchor. The dynamic information includes the following data: ship Maritime Mobile Service Identity (MMSI) in the form of a nine-digit identification number, navigation status, rate of turn, speed over ground (SOG), position of the ship and the corresponding position accuracy, course over ground (COG), true heading, and timestamp in Coordinated Universal Time (UTC) seconds.

The AIS transceiver transmits static and voyage-related information every $6 \mathrm{~min}$. The information transmitted includes the following data: seven-digit IMO ship identification number, radio call sign, name of the ship, type of the ship and the cargo, dimensions of the ship, location of the positioning system's antenna, type of the positioning system, draught of the ship, destination, and estimated time of arrival (ETA) in UTC.

Data encoding used for transmitting the AIS data utilizes a fixed, predetermined number of bits for each data item. However, the number of bits varies between data items: 6 bits for the message ID, 2 bits for the indicator of repeating a message, 30 bits for the MMSI, 4 bits for the navigation status, 8 bits for the rate of turn, 10 bits for the SOG, 1 bit for the indicator of the position accuracy, 28 bits for the longitude, 27 bits for the latitude, 12 bits for the COG, 9 bits for the heading, 6 bits for the UTC seconds, 4 bits for the regional use, 1 bit for the Receiver Autonomous Integrity Monitoring (RAIM) flag, and 19 bits for the communication status.

Each data item is here represented by an integer value. Data items containing realnumbered values have a predetermined number of digits $n$ after the decimal point assigned to them. The integer values are, thus, obtained by multiplying the original real-valued number by $10^{n}$. The integer value of each data item is then converted to the binary format, thus forming the 168-bit binary data sequence. The binary sequence is divided into groups of six bits, and encoding is performed on these groups, i.e., each six-bit binary number is assigned with the corresponding valid character from the American Standard Code for Information Interchange (ASCII) table. The ASCII code of the corresponding alphanumeric characters and symbols is finally transmitted.

Figure 4 depicts the method used for the AIS data encoding, showing an example of one record of the dynamic information message within the AIS position report, with a total of 168 bits divided into the six-bit sections. Bit groups are indicated in Figure 4a, along with the AIS data items they represent within the message. Moreover, Figure $4 \mathrm{a}$ also shows an 
example of the message in the form of the bit patterns with explanations of the information they contain, and the ASCII code characters assigned to each six-bit group. Finally, the transmitted AIS message obtained by the described data encoding is shown in Figure $4 \mathrm{~b}$.

\begin{tabular}{|c|c|c|c|c|c|c|c|c|}
\hline \multicolumn{8}{|c|}{$\begin{array}{l}\text { Bit position } \\
\qquad \begin{array}{r}\text { 6-bit } \\
\text { encoding }\end{array}\end{array}$} & Bit group \\
\hline $1-6:$ & 1 & & 0 & 0 & 0 & 0 & 1 & \multirow{6}{*}{$\begin{array}{l}\text { Bits } 1-6 \\
\text { Bits } 7-8 \\
\text { Bits } 9-38\end{array}$} \\
\hline $7-12:$ & $\mathbf{P}$ & & 0 & 0 & 0 & 0 & 0 & \\
\hline $13-18:$ & 0 & 0 & 0 & 0 & 0 & 0 & 0 & \\
\hline $19-24:$ & 0 & 0 & 0 & 0 & 0 & 0 & 0 & \\
\hline $25-30:$ & 0 & $\rightarrow 0$ & 0 & 0 & 0 & 0 & 0 & \\
\hline $31-36:$ & 0 & $\rightarrow 0$ & 1 & 1 & 1 & 1 & 1 & \\
\hline $37-42:$ & $\mathrm{h}$ & $\rightarrow 1$ & 1 & 0 & 0 & 0 & 0 & \multirow{4}{*}{$\begin{array}{l}\text { Bits } 39-42 \\
\text { Bits } 43-50 \\
\text { Bits } 51-60\end{array}$} \\
\hline $43-48:$ & 1 & & 0 & 0 & 0 & 0 & 1 & \\
\hline $49-54:$ & $I$ & & 1 & 1 & 0 & 0 & 1 & \\
\hline $55-60:$ & $\mathrm{T}$ & 1 & 0 & 0 & 1 & 0 & 0 & \\
\hline $61-66:$ & 1 & & 0 & 0 & 0 & 0 & 1 & \multirow{4}{*}{$\begin{array}{l}\text { Bit } 61 \\
\text { Bits } 62-89\end{array}$} \\
\hline $67-72:$ & $\mathbf{s}$ & 1 & 1 & 1 & 0 & 1 & 1 & \\
\hline $73-78:$ & $\mathrm{v}$ & 1 & 1 & 1 & 1 & 1 & 0 & \\
\hline $79-84:$ & $\mathrm{T}$ & & 0 & 0 & 1 & 0 & 0 & \\
\hline $85-90:$ & $\mathbf{P}$ & 1 & 0 & 0 & 0 & 0 & 0 & \multirow[t]{5}{*}{ Bits $90-116$} \\
\hline $91-96:$ & 2 & $\rightarrow 0$ & 0 & 0 & 0 & 1 & 0 & \\
\hline $97-102:$ & $r$ & $\rightarrow 1$ & 1 & 1 & 0 & 1 & 0 & \\
\hline 103-108: & $:$ & 0 & 0 & 1 & 0 & 1 & 0 & \\
\hline 109-114: & 4 & 0 & 0 & 0 & 1 & 0 & 0 & \\
\hline 115-120: & 3 & $\rightarrow 0$ & 0 & 0 & 0 & 1 & 1 & \multirow[t]{2}{*}{ Bits $117-128$} \\
\hline 121-126: & g & $\rightarrow 1$ & 0 & 1 & 1 & 1 & 1 & \\
\hline $127-132:$ & $r$ & $\rightarrow 1$ & 1 & 1 & 0 & 1 & 0 & \multirow{7}{*}{$\begin{array}{l}\text { Bits } 129-137 \\
\text { Bits } 138-143 \\
\text { Bits } 144-147 \\
\text { Bit } 148 \\
\text { Bit } 149 \\
\text { Bits } 150-168\end{array}$} \\
\hline 133-138: & $w$ & -1 & 1 & 1 & 1 & 1 & 1 & \\
\hline 139-144: & $\mathrm{b}$ & -1 & 0 & 1 & 0 & 1 & 0 & \\
\hline 145-150: & 0 & -0 & 0 & 0 & 0 & 0 & 0 & \\
\hline $151-156:$ & 5 & $\rightarrow 0$ & 0 & 0 & 1 & 0 & 1 & \\
\hline $157-162:$ & $q$ & $\rightarrow 1$ & 1 & 1 & 0 & 0 & 1 & \\
\hline $162-168:$ & 4 & $\rightarrow 0$ & 0 & 0 & 1 & 0 & 0 & \\
\hline
\end{tabular}

Data item

Message ID

Repeat indicator

User ID(MMSI)

Navigation status

Rate of turn

Speed over ground $(\times 10)$

Position accuracy

Longitude in 1/10000 minutes

Latitude in $1 / 10000$ minutes

Course over ground in $\times 10$ degrees

Heading

Timestamp (UTC second)

Regional use

Unused

RAIMflag

Communication status
Example

$000001=$ message ID 1

2 = message repeated twice $00000000000000000000000111111=127$

$0000=$ underway using engine

$00000101=+1.1^{\circ} / \mathrm{min}$

$1001100100=61.2$ knots

$0=$ Low (Error over $10 \mathrm{~m}$ )

$0000111101111111010010010000=27^{\circ} 5^{\prime}$ East

$000001011101000101000010000=5^{\circ} 5^{\prime}$ North

$001110111111=95.9^{\circ}$ true

$101011111=351^{\circ}$ true

$110101=53 \mathrm{~s}$

$0000=$ no regional application

$0=$ RAIMnot in use

$00=$ UTC Direct

$001=1$ frame remaining until a new slot is selected $01111001000100=01111: 0010001=15: 17$ UTC

(a)

! AIVDM, 1, 1, , A, 1p0000h1IT1svTp2r:43grwb05q4, 0*01

(b)

Figure 4. AIS data encoding: (a) Example of one record of the AIS position report message; (b) Obtained encoded message.

The described data encoding converts the decimal numeric values to the ASCII code in the following way: decimal numbers in the range 0-39 are converted to hexadecimal numbers in the range $0 \times 30-0 \times 57$, while those in the range 40-63 correspond to the hexadecimal range $0 \times 60-0 \times 77$. The six-bit binary field conversion used for AIS data encoding is proposed by the International Electrotechnical Commission (IEC) in the document IEC 61162-1 (Table C.1) [38]. IEC 61162-1 represents the international standard for the digital interfaces used in maritime navigation and radiocommunication equipment and systems, particularly in single talker and multiple listener systems.

\section{Materials and Methods}

\subsection{Shipboard Data Acquisition}

The data compression method proposed in this paper needs to be experimentally validated on the actual shipboard data. Therefore, the data were collected on board the Training Ship (TS) Fukae Maru. This ship is operated by Kobe University, Japan, and is used for training, research, and conducting experiments. The research includes the development, implementation, and testing of various intelligent ship concepts, such as Heading Control System (HCS) and Track Control System (TCS) [39], a practical and easy-to-implement dynamic positioning (DP) system [40], and a tablet-supported control system [41]. The ship is equipped with numerous state-of-the-art electronic devices and systems that enable advanced control functions and collecting large amounts of data 
from various sources [42,43]. Figure 5a shows TS Fukae Maru, while Figure 5b,c show the examples of navigation screen and engine monitoring screen available in the control room, respectively. In addition, the data acquisition devices are integrated with the advanced shipboard Local Area Network (LAN) [44], whose configuration diagram is depicted in Figure 6.

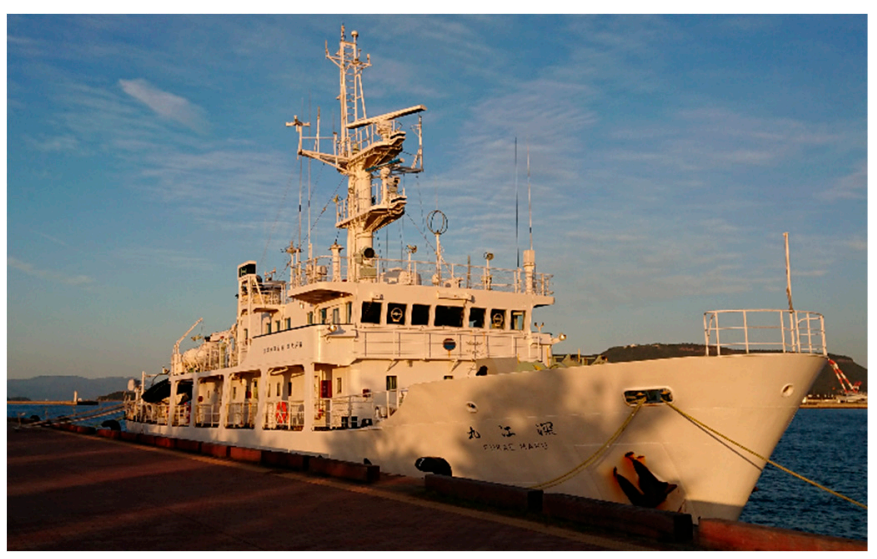

(a)

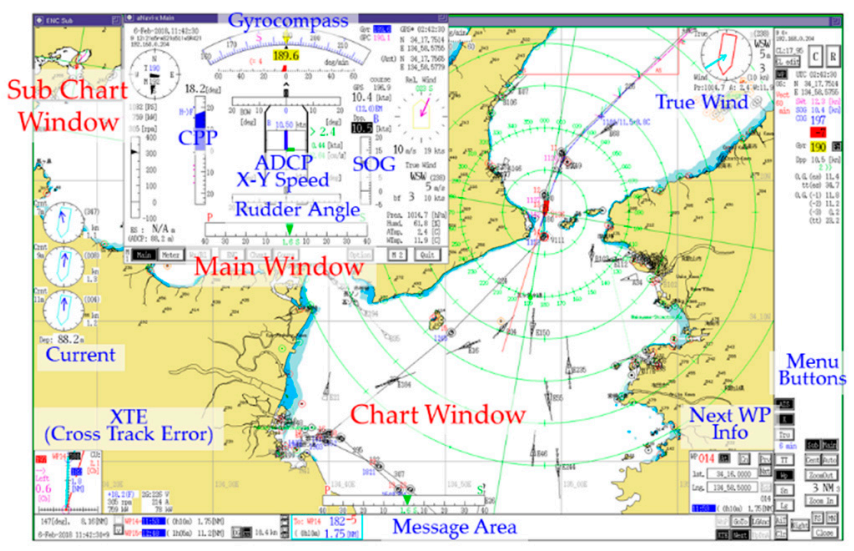

(b)

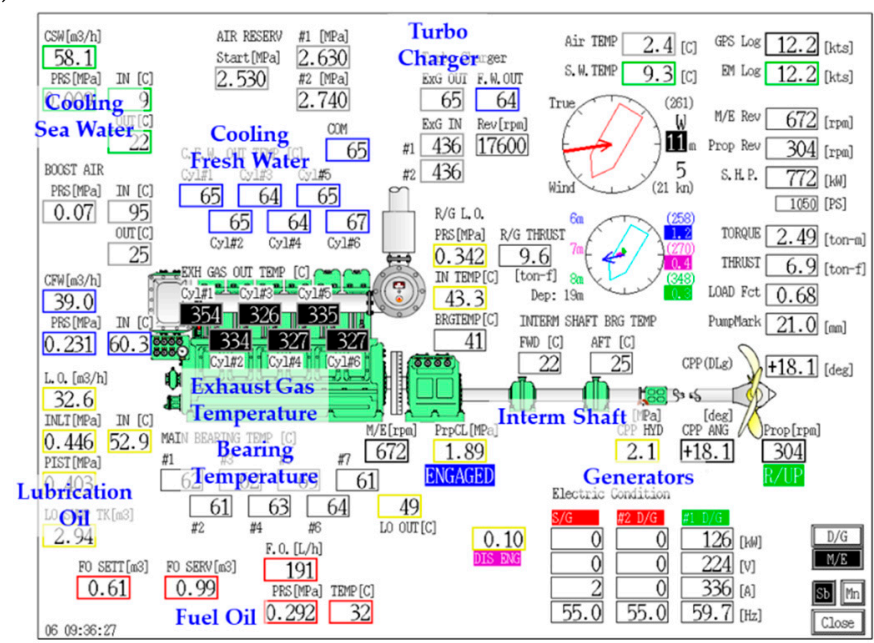

(c)

Figure 5. Examples of advanced ship systems used for data acquisition: (a) TS Fukae Maru; (b) Navigation screen; (c) Engine monitoring screen.

Digital data are collected by various devices and shared via LAN. These include measurements from navigation instruments, engine monitoring sensors, environmental sensors, and targets data. Navigation data consist of Global Positioning System (GPS) data and data from GPS compass, magnetic compass, and gyrocompass, while environmental data refer to measurements of various external variables, such as data from the Acoustic Doppler Current Profiler (ADCP) and anemometer. Engine-related data include sensors for monitoring engine operation, such as temperatures of various engine parts, flow rate, and pressure, whereas targets data consist of radar and AIS data.

The approximate total number of data items collected and transmitted is 450 , including approximately 50 measurement channels for navigation data, 50 channels for environmental data, and 350 channels for engine-related data. Navigation data are collected and transmitted every $0.2-1 \mathrm{~s}$, environmental data at 1-2 s intervals, while engine-related data are transmitted every $2 \mathrm{~s}$.

Figure 7 shows an example of one line of shipboard data sent from TS Fukae Maru, where each line of data represents one sentence sent by the device, i.e., one data record. Figure 8 explains the structure that is characteristic for each line of data sent. As shown 
in Figure 8, each line of data begins with a timestamp that contains, from left to right, information about the year (YYYY), month (MM), day (DD), hour (HH), minute (MM), second (SS), and millisecond (mmm). In addition, each line also contains the device code (D), which is used to identify the data source. Finally, the main information is contained within the NMEA sentence.

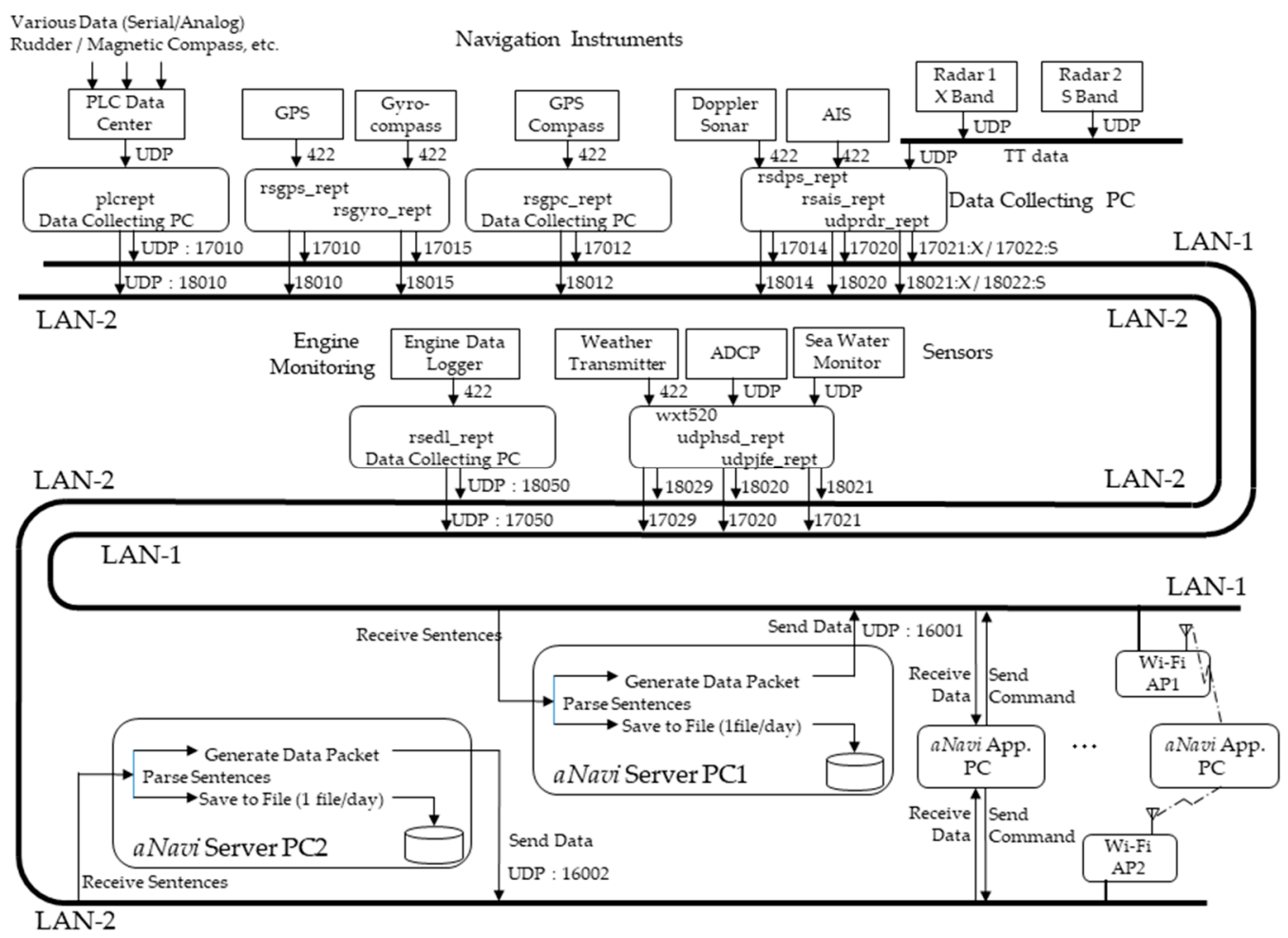

Figure 6. Configuration of the shipboard LAN for data acquisition and recording.

\section{3, \$GPVTG $, 57.9, \mathrm{~T}, 63.9, \mathrm{M}, 0.9, \mathrm{~N}, 1.7, \mathrm{~K} * 46$}

Figure 7. Example of one line of transmitted shipboard data.

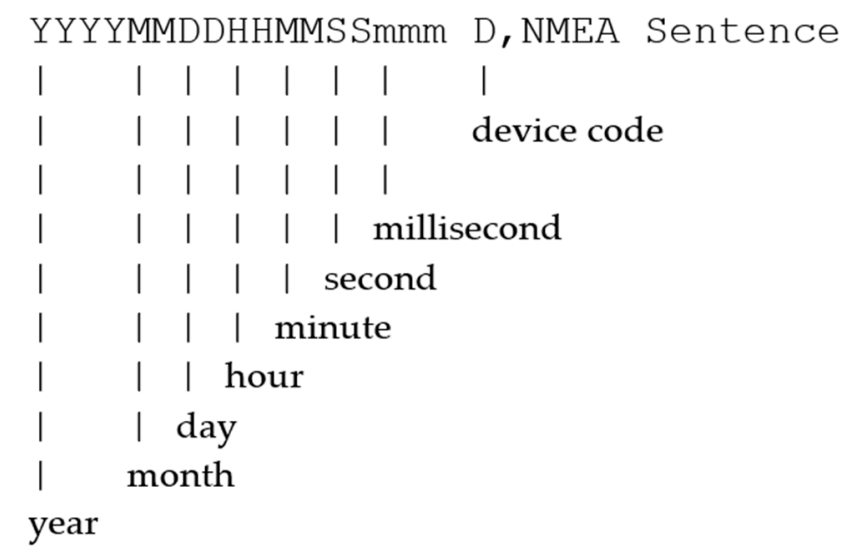

Figure 8. Structure of one line of transmitted shipboard data.

NMEA-0183 data format protocol proposed by the National Marine Electronics Association (NMEA) represents a standard for interfacing marine electronic devices, navigation instruments, and communications equipment [45]. This protocol supports one-way serial data transmission from a single talker to one or more listeners, where talker and listener 
refer to a device that sends or receives data from other devices. Data are represented in printable ASCII characters form, while messages have typical lengths in the range between 11 and 79 characters [45]. Figure 9 shows the structure of the NMEA data sentence. Each sentence contains, from left to right, delimiter character " $\$$ ", address field denoting talker identifier (TT) and sentence formatter (SSS), delimiter character ",", text representing data content, as well as the delimiter character " $*$ " followed by the checksum field (xx) consisting of two bytes in a hexadecimal format.

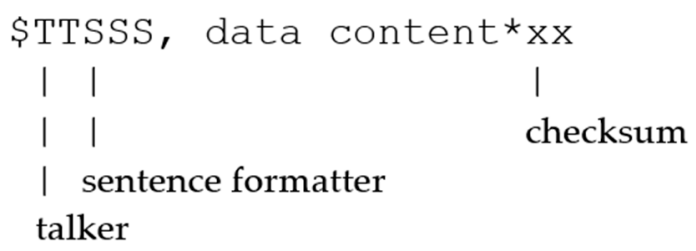

Figure 9. Structure of the NMEA data format.

Table 1 contains codes for data source devices. These device codes are used to identify data items in the transmitted data and are specific to the shipboard data acquisition and transmission system of TS Fukae Maru, as this advanced system is not yet widely used on larger merchant vessels.

Table 1. Codes of the data source devices.

\begin{tabular}{cc}
\hline Device Code & Data Source Device \\
\hline 0 & Voyage Data Recorder (VDR) \\
1 & GPS \\
2 & GPS compass \\
3 & GPS compass \\
4 & Doppler sonar \\
5 & Gyrocompass \\
6 & Magnet compass \\
7 & Electromagnetic (EM) log \\
8 & Doppler log \\
9 & Accelerometer \\
N & Navigation data collection equipment \\
D & Weather (Analog) \\
A & AIS \\
R & Radar 1 \\
S & Radar 2 \\
W & Weather transmitter \\
E & Engine data logger \\
C & Central Processing Unit (CPU) control system \\
B & Acoustic Doppler Current Profiler (ADCP) \\
\hline
\end{tabular}

The amount of data collected by all devices that make up the advanced data acquisition system reaches about 7.5 million lines in one day of the ship's voyage. Therefore, about 87 lines of data are transmitted in NMEA sentence format in every second of ship operation. The total size of data received from devices, transmitted, and recorded as ASCII text in one day is about $400 \mathrm{MB}$. In order to transfer the data collected onboard to the land, we consider using a data line like Inmarsat FB, so this transmission rate is not unfeasible with the current bandwidth of satellite communications. However, the relatively high cost of using satellite communications and their already high utilization must be considered. In addition, the demand for Internet use by the ship's crew and passengers is increasing rapidly. On larger cruise ships, this is a challenging task due to the limitations of narrowband satellite communications. Therefore, methods are needed to reduce the amount of data transmitted onboard. 


\subsection{Proposed Shipboard Data Compression Method}

Fixed-record-length data encoding methods, such as the previously described method used for AIS data encoding, require all data to be sent periodically in a predetermined order each time data are transmitted. Due to the predetermined order, data only need to be lined up with a delimiter character, such as a comma. However, the shipboard data are collected by various measuring devices at short time intervals. Some data items, such as the ship's position and heading, change their values rapidly, while others do not change for several seconds or even minutes. Thus, transmitting data items with no change in value may be redundant.

Therefore, reducing the amount of shipboard data transferred can be achieved by utilizing the variable-record-length methods, which send only the data items that have changed since the last transmission, thus preventing unnecessary transmitting data without a change in value. These methods require specifying which data items to send each time, which is achieved by attaching tags to data values and, thus, identifying the corresponding data items. Furthermore, to avoid possible situations in which data reception starts later and, thus, there is no information about the data that have not changed for some time, the variable-record-length methods periodically send all data.

The variable-record-length data encoding method proposed in this paper is described next. The method is based on the binary encoding of shipboard data. Shipboard data are digital numeric data that can be represented in binary or text format. Although the ASCII text data representation might be simpler to comprehend, the binary representation is more efficient as it reduces the number of bits required for numeric values with multiple digits. Using the binary format for data representation requires defining a technique to convert the integer values to the corresponding binary values.

First, the number of bits used to represent integer values and the number of words allowed for each data item must be defined. Similar to the previously described AIS data encoding technique, the method proposed in this paper performs a six-bit encoding, and the resulting ASCII code is transmitted. The maximum binary field length for the data item representation is defined in the range of one to five six-bit words. Figure 10 shows various allowed lengths of binary fields and the corresponding data value ranges that can be expressed using them. In addition to the defined minimum and maximum numeric values, each range can also be positive only or have both positive and negative values. The appropriate value range ID denotes this property. For example, the minimum length of the binary field used to represent one data item is one six-bit word. One six-bit word enables the representation of numeric values either in the range of $0-63$ or in the range of $-32-31$, marked by value range IDs of 1 and -1 , respectively. On the other hand, the maximum binary field length of five six-bit words corresponds to the numeric value range of 0-1 073741823 or $-536870912-536870911$, denoted by 5 or -5 , respectively.

If thus encoded binary data are transmitted each time for each data item, the total amount of data transferred will be constant. However, to achieve data compression, the method proposed in this paper applies differential binary encoding where only data items whose value has changed since the last transmission are encoded and transmitted. The proposed approach results in the data format depicted in Figure 11. As shown in Figure 11, one data record consists of six six-bit words used to denote a timestamp (YYMMDD and HHMMSS), two words to define a total number of data items transmitted in the current data record, two words per item to specify each data item transmitted, and, finally, binary words representing data values with various number of words for individual data items. 


\begin{tabular}{|c|c|c|c|c|c|c|}
\hline \multicolumn{5}{|c|}{ Length of binary field } & Data value range & Value range ID \\
\hline bbbbbb & & & & & $0-63 /-32-31$ & $1 /-1$ \\
\hline \multicolumn{7}{|l|}{6 bits } \\
\hline bbbbbb & bbbbbb & & & & $0-4095 /-2048-2047$ & $2 /-2$ \\
\hline \multicolumn{7}{|c|}{12 bits } \\
\hline bbbbbb & bbbbbb & bbbbbb & & & $0-262143 /-131072-131071$ & $3 /-3$ \\
\hline \multicolumn{7}{|c|}{18 bits } \\
\hline bbbbbb & bbbbbb & bbbbbb & bbbbbb & & $0-16777215 /-8388608-8388607$ & $4 /-4$ \\
\hline \multicolumn{7}{|c|}{24 bits } \\
\hline bbbbbb & bbbbbb & bbbbbb & bbbbbb & bbbbbb & $0-1073741823$ / -536 $870912-536870911$ & $5 /-5$ \\
\hline
\end{tabular}

Figure 10. Lengths of binary fields composed of six-bit words and the corresponding data value ranges.

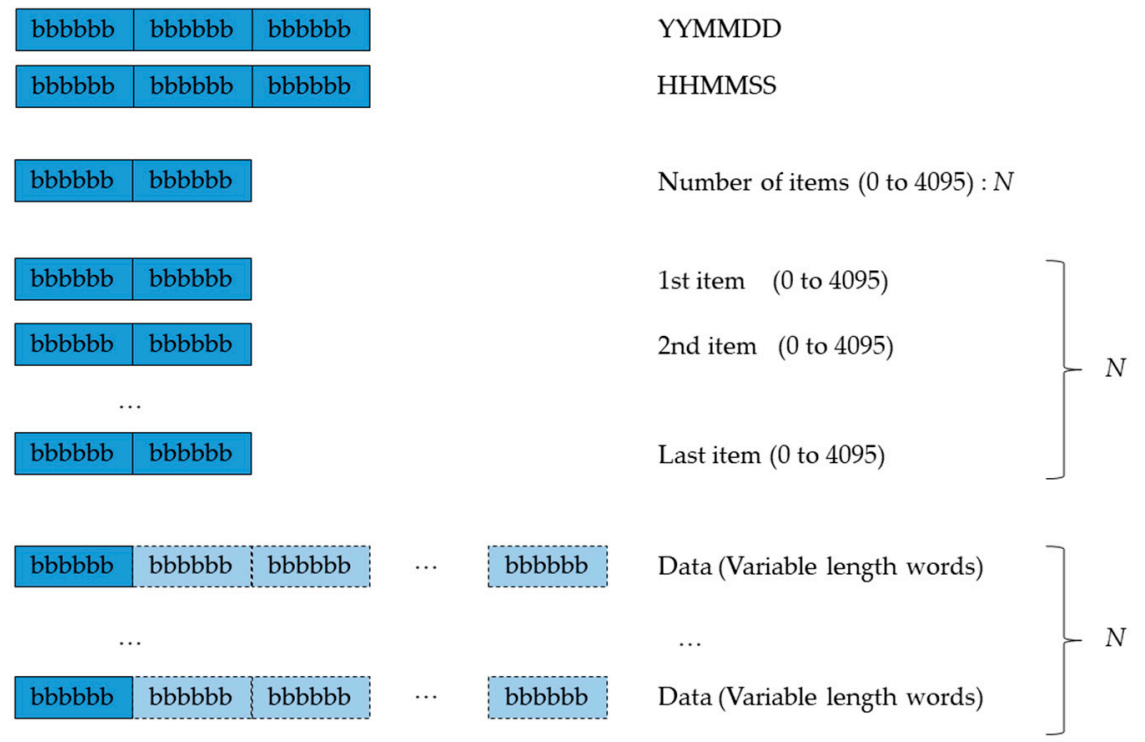

Figure 11. Proposed format of one data record.

The properties of data items that will be used for their representation need to be defined. These properties are constant and are thereby gathered in the data item table, prepared and recorded in advance. Figure 12a shows the table of data items used on board TS Fukae Maru, where one line defines the properties of one data item. The structure of such data line is illustrated in Figure $12 \mathrm{~b}$ on the example of a data item representing the COG. As shown in Figure 12b, each line contains the following information: the data item number, the number of digits after the decimal point, the data item name, the unit, the value range ID, and the minimum and the maximum value of the data item range. Commas separate these line elements. 


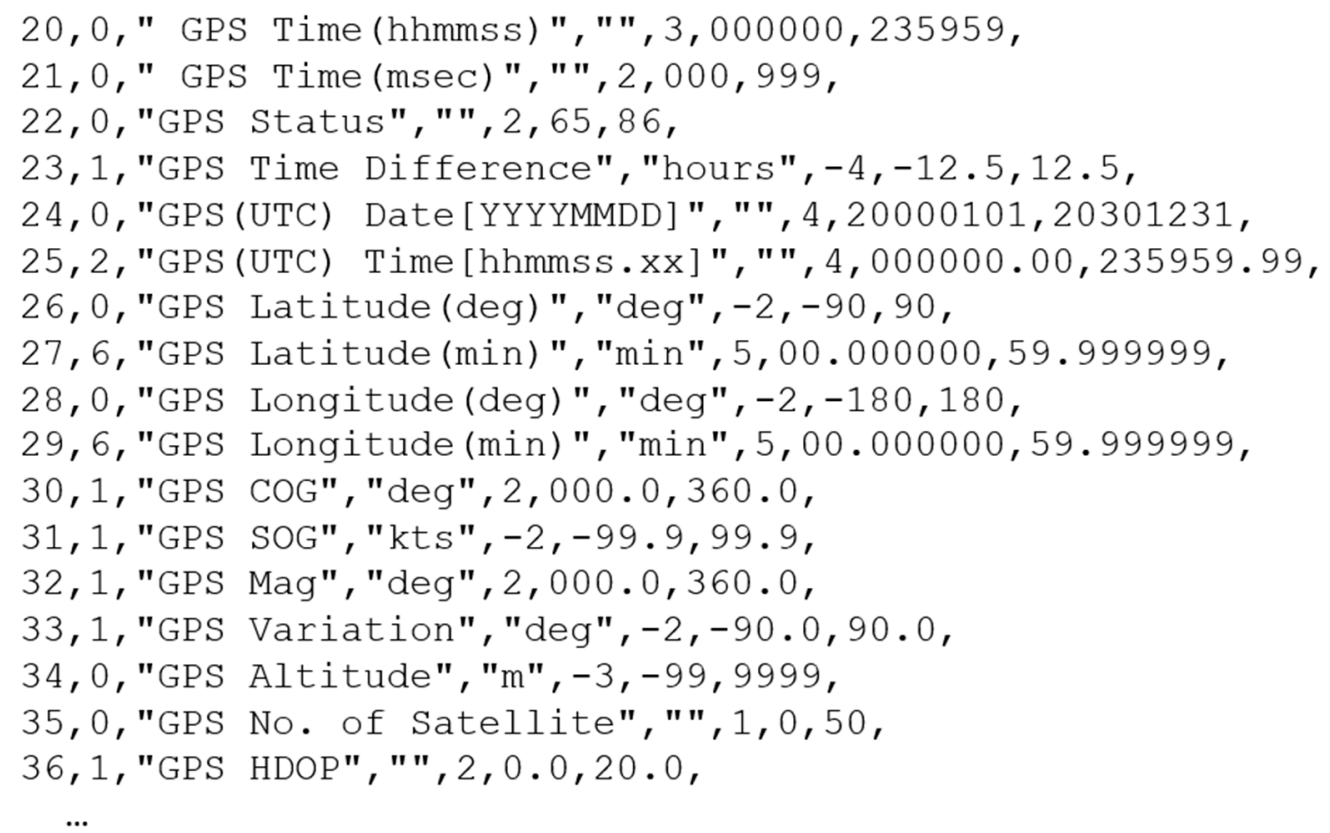

(a)

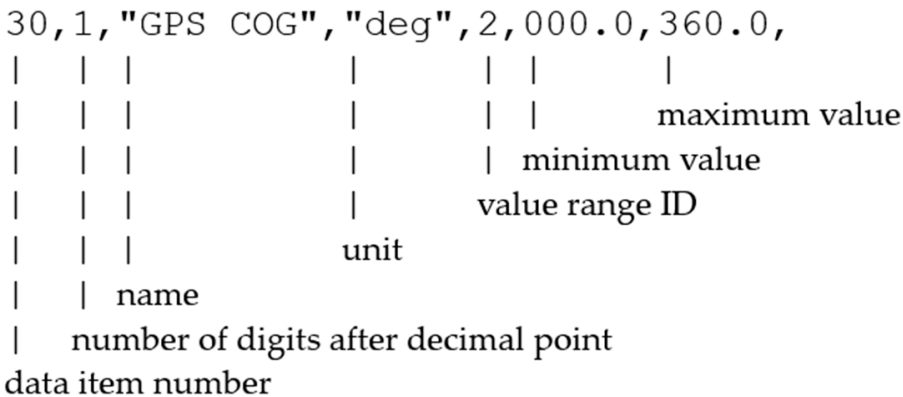

(b)

Figure 12. Data items definition: (a) Table of data items for TS Fukae Maru; (b) Structure of a data line defining properties of one data item.

The binary patterns resulting from binary data encoding are converted to ASCII text, where an ASCII character is assigned to each group of six bits. Thus, obtained text forms one data record. If the obtained text is longer than 60 characters, it is divided into multiple lines. Since six-bit words are used, a total of 64 ASCII characters is required for data encoding. The characters used by the proposed encoding technique are shown in Table 2 as the shaded area of the ASCII code table. As shown in Table 2, the proposed technique utilizes 64 consecutive ASCII characters, thus enabling the binary values to be converted into hexadecimal by simply adding a value of $0 \times 30$. Therefore, the proposed conversion is more straightforward than the one employed by the AIS data encoding. Table 3 shows the proposed six-bit binary field conversion table.

The proposed data record format also includes a two-digit hexadecimal checksum appended to the message. The checksum is computed by performing the exclusive or (XOR) operation on all ASCII code characters in the message following the "!" character. Finally, one line of the data record in the proposed format starts with the "!" character and includes the timestamp (HHMMSSsss) denoting hours, minutes, seconds, and milliseconds, the serial number used when the transmitted data text is divided into several lines, the text obtained by the six-bit data encoding, "**” character, and the checksum. Listed data line elements, except the checksum, are separated by comma (", ,") delimiters. The flowchart of the proposed data encoding method and the resulting format of the transmitted data are shown in Figure 13. 
Table 2. Range for the proposed six-bit binary encoding in the ASCII code table (shaded).

\begin{tabular}{|c|c|c|c|c|c|c|c|c|}
\hline \multirow{2}{*}{$\begin{array}{c}\text { Lower } \\
\text { Digit }\end{array}$} & \multicolumn{8}{|c|}{ Upper Digit } \\
\hline & 0 & 1 & 2 & 3 & 4 & 5 & 6 & 7 \\
\hline 0 & NUL & DLE & SP & 0 & $@$ & $\mathrm{P}$ & ' & $\mathrm{p}$ \\
\hline 1 & $\mathrm{SOH}$ & DC1 & $!$ & 1 & A & $\mathrm{Q}$ & a & $\mathrm{q}$ \\
\hline 2 & STX & DC2 & $"$ & 2 & B & $\mathrm{R}$ & $\mathrm{b}$ & $\mathrm{r}$ \\
\hline 3 & ETX & DC3 & $\#$ & 3 & $\mathrm{C}$ & $\mathrm{S}$ & c & $\mathrm{s}$ \\
\hline 4 & EOT & DC4 & $\$$ & 4 & $\mathrm{D}$ & $\mathrm{T}$ & d & $\mathrm{t}$ \\
\hline 5 & ENQ & NAK & $\%$ & 5 & $\mathrm{E}$ & $\mathrm{U}$ & e & $\mathrm{u}$ \\
\hline 6 & ACK & SYN & $\&$ & 6 & $\mathrm{~F}$ & $\mathrm{~V}$ & $\mathrm{f}$ & $\mathrm{v}$ \\
\hline 7 & BEL & ETB & ' & 7 & G & W & $\mathrm{g}$ & $\mathrm{w}$ \\
\hline 8 & BS & CAN & ( & 8 & $\mathrm{H}$ & $x$ & $\mathrm{~h}$ & $x$ \\
\hline 9 & HT & EM & ) & 9 & I & $\mathrm{Y}$ & $\mathrm{i}$ & $\mathrm{y}$ \\
\hline $\mathbf{a}$ & LF & SUB & * & $:$ & $\mathrm{J}$ & $\mathrm{Z}$ & j & $\mathrm{z}$ \\
\hline $\mathbf{b}$ & VT & ESC & + & ; & $\mathrm{K}$ & {[} & $\mathrm{k}$ & \{ \\
\hline c & $\mathrm{FF}$ & FS & , & $<$ & $\mathrm{L}$ & 1 & 1 & i \\
\hline d & $\mathrm{CR}$ & GS & - & $=$ & $\mathrm{M}$ & ] & $\mathrm{m}$ & \} \\
\hline e & $\mathrm{SO}$ & RS & . & $>$ & $\mathrm{N}$ & 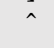 & $\mathrm{n}$ & $\sim$ \\
\hline f & SI & US & / & $?$ & $\mathrm{O}$ & _ & o & DEL \\
\hline
\end{tabular}

Table 3. Proposed six-bit binary field conversion table.

\begin{tabular}{|c|c|c|c|}
\hline Valid Character & Binary Field & Valid Character & Binary Field \\
\hline 0 & 000000 & $\mathrm{P}$ & 100000 \\
\hline 1 & 000001 & Q & 100001 \\
\hline 2 & 000010 & $\widehat{\mathrm{R}}$ & 100010 \\
\hline 3 & 000011 & $S$ & 100011 \\
\hline 4 & 000100 & $\mathrm{~T}$ & 100100 \\
\hline 5 & 000101 & $\mathrm{U}$ & 100101 \\
\hline 6 & 000110 & $\mathrm{~V}$ & 100110 \\
\hline 7 & 000111 & $\mathrm{~W}$ & 100111 \\
\hline 8 & 001000 & $x$ & 101000 \\
\hline 9 & 001001 & $\mathrm{Y}$ & 101001 \\
\hline$:$ & 001010 & Z & 101010 \\
\hline ; & 001011 & {[} & 101011 \\
\hline$<$ & 001100 & 1 & 101100 \\
\hline$=$ & 001101 & ] & 101101 \\
\hline$>$ & 001110 & 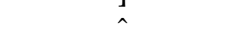 & 101110 \\
\hline$?$ & 001111 & _ & 101111 \\
\hline$@$ & 010000 & 7 & 110000 \\
\hline A & 010001 & a & 110001 \\
\hline $\mathrm{B}$ & 010010 & $\mathrm{~b}$ & 110010 \\
\hline $\mathrm{C}$ & 010011 & c & 110011 \\
\hline $\mathrm{D}$ & 010100 & $\mathrm{~d}$ & 110100 \\
\hline $\mathrm{E}$ & 010101 & $\mathrm{e}$ & 110101 \\
\hline $\mathrm{F}$ & 010110 & $\mathrm{f}$ & 110110 \\
\hline G & 010111 & $\mathrm{~g}$ & 110111 \\
\hline $\mathrm{H}$ & 011000 & $\mathrm{~h}$ & 111000 \\
\hline I & 011001 & i & 111001 \\
\hline $\mathrm{J}$ & 011010 & j & 111010 \\
\hline $\mathrm{K}$ & 011011 & $\mathrm{k}$ & 111011 \\
\hline $\mathrm{L}$ & 011100 & 1 & 111100 \\
\hline $\mathrm{M}$ & 011101 & $\mathrm{~m}$ & 111101 \\
\hline $\mathrm{N}$ & 011110 & $\mathrm{n}$ & 111110 \\
\hline $\mathrm{O}$ & 011111 & $\mathrm{o}$ & 111111 \\
\hline
\end{tabular}




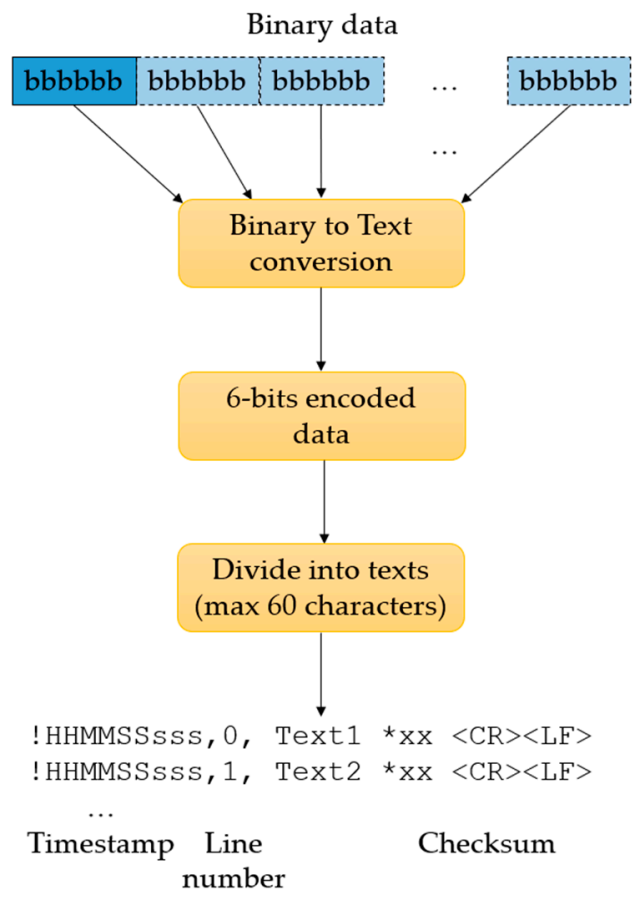

Figure 13. Flowchart of the proposed shipboard data encoding method.

\section{Results and Discussion}

The performance of the proposed shipboard data compression method has been experimentally tested on the data collected on board TS Fukae Maru. The data were collected during the ship's voyage in 2019. The recorded data cover 22 days, and the measurements were taken $24 \mathrm{~h}$ a day. In this experiment of applying the proposed differential binary encoding technique, all data items were also transmitted once every minute to ensure all information is received regardless of when the reception started.

Figure 14 shows an example of the shipboard data collected during a random time of $1 \mathrm{~s}$. The data are transmitted in their original format based on the NMEA sentences. As shown in Figure 10, this format requires a total of 75 lines to represent this particular $1 \mathrm{~s}$ of data. On the other hand, Figure 15 shows an example of the onboard data encoded using the proposed six-bit differential binary encoding scheme. As shown in Figure 15, the same data as in Figure 14 can be represented with only 11 lines instead of 75 lines, using the proposed encoding technique. Moreover, the next $3 \mathrm{~s}$ of data are encoded using only 2, 3, and 2 lines of code, respectively. The significant reduction in the number of data lines required is achieved by encoding and transmitting only data items that have changed their values.

As shown in Figure 15, when sending the compression result, the two-digit hexadecimal number following "**" is added as a checksum at the end of each line. This checksum is calculated in the same manner as the checksum field of the NMEA-0183, enabling error detection. By doing this, the code can detect errors.

Table 4 provides values for the size of the shipboard data collected during each day of the ship's voyage and for the corresponding transmission rates required to transmit those data. The data collected over 22 days add up to 8277905025 bytes when transmitted and recorded using the NMEA sentence standard in the form of the ASCII text. On average, 376268410 bytes of data are collected per day with a standard deviation (st. dev.) of 57362724 bytes, requiring an average data transmission rate of 34840 bps with a standard deviation of 5311 bps. The maximum transmission rate required was recorded on day 14 and was $46097 \mathrm{bps}$, whereas the minimum required transmission rate of $28316 \mathrm{bps}$ was recorded on day 19. 
$201908251200000065, \$ T I R O T,-017.2, A \times 12$

201908251200000092 2, \$GPVTG, 060.6, T, , 001.0, N, 001.8, $K^{*} 25$

201908251200000213, \$GPVTG, $57.9, \mathrm{~T}, 63.9, \mathrm{M}, 0.9, \mathrm{~N}, 1.7, \mathrm{~K} * 46$

20190825120000025 2, \$GPRMC, 025957, A, 3215.1056, N, 13309.9150,E, 001.0,061, 250819, *22

$201908251200000352, \$ \mathrm{GPDTM}, \mathrm{W} 84,0.0, \mathrm{~N}, 0.0, \mathrm{E},+0.0, \mathrm{~W} 84 * 44$

201908251200000522 2, \$GPGSA, A, 3,17, 19,06,28,23,00,00,00,00,00,00,00,04.2,01.4,03.8*09

$20190825120000052 \mathrm{E}, \$ 000008,39035860,282,20028,4221,21017,1449,436,424 * 31$

201908251200000712 , \$GPGSV, 3, 1, 10,17,70,349,54,19,54,330,50,06,41,296,50,28,41, 203,47*7E

20190825120000081 1, \$GPGGA, 030000,3215.1086, N, 13309.9192, E, 1, 11, 1.5, 21, M, , M, , *77

201908251200000811, SCCVTG, $61.23, \mathrm{~T}, \ldots .97, \mathrm{~N}, 1.80, \mathrm{~K} * 3 \mathrm{~b}$

$201908251200000811, \$ C C V L W, 411.96, N, 411.96, N * 4 d$

201908251200000892 2, \$GPGSV, 3,2,10,03,40,043,42,23,31,100,46,09,25,144,41,22,19, 044,44*7D

201908251200000963, \$GPZDA, 030000,09,01,2000,-09,00*65

20190825120000108 2, SGPGSV, 3, 3,10,01,13,069,42,11,12,095,39,00,00,000,00,00,00,000,00*77

201908251200001202 , \$GPGLL, 3215.1056, N, 13309.9150, E, 025957.00, A*0A

$201908251200001202, \$ \mathrm{CCVTG}, 65.84, \mathrm{~T},, 0.97, \mathrm{~N}, 1.79, \mathrm{~K} * 34$

$201908251200001202, \$ C C V L W, 412.24, N, 412.24, N * 4 d$

201908251200001482, SGPHDT, $004.3, \mathrm{~T} * 32$

201908251200001542, 2, $\mathrm{GPROT},-0016.0, \mathrm{~A} * 2 \mathrm{~B}$

$201908251200001581, \$ \mathrm{GPVTG}, 64.5, \mathrm{~T}, 71.3, \mathrm{M}, 0.9, \mathrm{~N}, 1.7, \mathrm{~K} * 43$

201908251200001622 , \$PFEC, GPatt, $4.3,-2.1,-1.9 * 44$

20190825120000167 5, \$HEHDT, $004.9, T * 22$

201908251200001702 , SPFEC, GPhve, $+0.066, A^{*} 14$

201908251200002065, STIROT, $-016.1, A^{*} 10$

201908251200002253 3, \$GPGGA, $030000,3215,1086, \mathrm{~N}, 13309.9204, \mathrm{E}, 1,10,2.4,54, \mathrm{M}, \mathrm{M}$, , *7A

201908251200002331 , \$GPZDA, 030000,25,08,2019,-09,00*6A

201908251200002790 , \$WIXDR, P, 1.0111, B, 0, C, 26.6, C, 0, H, 70.0, P, O C, 29.3, C, 1*56

201908251200002790, \$AGRSA, $-34.06, \mathrm{~A}, * 05$

20190825120000316 S, \$RARSD, $0.000,000.0,0.263,252.2, \ldots, 6.382,130.7,12.00, N, N * 5 D$

201908251200003183, SGPGLL, 3215.1086, N, 13309.9204, E, 030000, A*24

201908251200003482, 2, \$GPHDT, 004.2, T*33

201908251200003531 , \$GPGNS, $030000,3215.1086, N, 13309.9192, \mathrm{E}, \mathrm{A}, 11,1.5,21, \ldots * 1 \mathrm{C}$

201908251200003542, SGPROT, $-0016.3, A * 28$

20190825120000362 2, \$PFEC, GPatt, $4.2,-2.1,-1.8 * 44$

201908251200003685, SHEHDT, $004.8, \mathrm{~T} * 23$

201908251200003702, SPFEC, GPhve, $+0.048, A * 18$

201908251200003813, \$PFEC, GPatt, $5.1,+2.1,-2.1 * 4 \mathrm{~A}$

201908251200004015 , \$TIROT, $-015.2, A^{*} 10$

$201908251200004110, \$ W I X D R, P, 1.0111, B, 0, C, 26.6, C, 0, H, 69.9, P, 0, C, 29.3, C, 1 * 57$

201908251200004203, SGPROT, $-16.7, \mathrm{~A} * 2 \mathrm{C}$

201908251200004515, 5HEHCR, 004.8,A, N, 00.0*67

201908251200004744 , \$VDVBW, $0.49,0.69, \mathrm{~A}, 11.54,-0.89, \mathrm{~V}, 0.85, \mathrm{~A},-0.89, \mathrm{~V}^{*} 6 \mathrm{E}$

201908251200004823, \$PFEC, GPatt, $5.1,+2.0,-2.0 * 4 \mathrm{~A}$

20190825120000522 3,\$GPROT, $-16.0, \mathrm{~A} * 2 \mathrm{~B}$

201908251200005390 , sVMVHW, 005.0, T, 022.0, M, 0.3, N, 0.6, K*4e

20190825120000544 4, \$VDVHW, 5.1, T, , M, 0.84, N, 1.56, K*63

201908251200005843, SPFEC, GPatt, $5.0,+1.9,-1.8 * 4 \mathrm{~A}$

201908251200006044, SVDVDR, $117.6, \mathrm{~T}, \mathrm{M}, 0.13, \mathrm{~N} * 36$

201908251200006065, TTIROT, $-014.6, \mathrm{~A} * 15$

201908251200006243 , \$GPROT, $-15.4, \mathrm{~A} * 2 \mathrm{C}$

201908251200006854, sVDVLW, $11491.435, \mathrm{~N}, 413.045, \mathrm{~N},, \mathrm{~N}, \mathrm{~N} * 56$

201908251200006870 , SWIVWR, $98, \mathrm{~L}, 4, \mathrm{~N}, 7, \mathrm{M}, 25, \mathrm{~K} * 4 \mathrm{C}$

201908251200007053 , \$PFEC, GPatt, 5.0,+1.8, $-1.7 * 44$

201908251200007453, SGPROT, $-15.0, \mathrm{~A} * 28$

$201908251200007482, \$ G P H D T, 004,1, T * 30$

201908251200007542, , \$GPROT, $-0016.5, \mathrm{~A} * 2 \mathrm{E}$

20190825120000762 2, \$PFEC, GPatt, 4.1,-2.1,-1.5*4A

201908251200007675, SHEHDT, 004.7, T*2C

201908251200007702 , SPFEC, GPhve, +0.017, A*12

20190825120000806 5, \$TIROT, $-014.2, \mathrm{~A} * 11$

201908251200008120 , \$WIXDR, P, $1.0111, \mathrm{~B}, 0, \mathrm{C}, 26.6, \mathrm{C}, 0, \mathrm{H}, 69.8, \mathrm{P}, 0, \mathrm{C}, 29.3, \mathrm{C}, 1 * 56$

201908251200008521 , \$GPDTM, W $84,, 00.0000, \mathrm{~N}, 00.0000, \mathrm{E}, \mathrm{W} 84 * 41$

201908251200009053, \$PFEC, GPatt, $4.9,+1.7,-1.5 * 41$

20190825120000923 0, \$WIXDR, P, 1.0111, B, 0, C, 26.6, C, 0, H, 69.7, P, 0, C, 29.3, C, 1*59

201908251200009453, 3GPROT, $-14.8, \mathrm{~A} * 21$

$201908251200009482, \$ \mathrm{GPHDT}, 004.1, \mathrm{~T} * 30$

$201908251200009542, \$ \mathrm{GPROT},-0016.1, \mathrm{~A} \star 2 \mathrm{~A}$

201908251200009622 , \$PFEC, GPatt, $4.1,-2.2,-1.4 * 48$

201908251200009675, \$HEHDT, $004.7, \mathrm{~T} * 2 \mathrm{C}$

201908251200009702 2, SPFEC, GPhve, $+0.017, \mathrm{~A} * 12$

201908251200009802, \$GPZDA, 030000.00,25,08,2019,*60

20190825120000981 1, \$GPGGA, $030001,3215.1087, \mathrm{~N}, 13309.9195, \mathrm{E}, 1,11,1.5,21, \mathrm{M}, \mathrm{M}$, , *70

$201908251200009811, \$ C C V T G, 57.52, T, 1,0.94, \mathrm{~N}, 1.74, \mathrm{~K} * 30$

201908251200009811 , \$CCVLW, $411.97, \mathrm{~N}, 411.97, \mathrm{~N} * 4 \mathrm{~d}$

201908251200009982 2, \$GPGGA, 025958,3215.1056, N, 13309.9152, E, 2, 05, 01, +0006, M, $+032, \mathrm{M}, 00,0000 * 6 \mathrm{~F}$

Figure 14. Example of $1 \mathrm{~s}$ of the shipboard data in the original NMEA sentence format. 


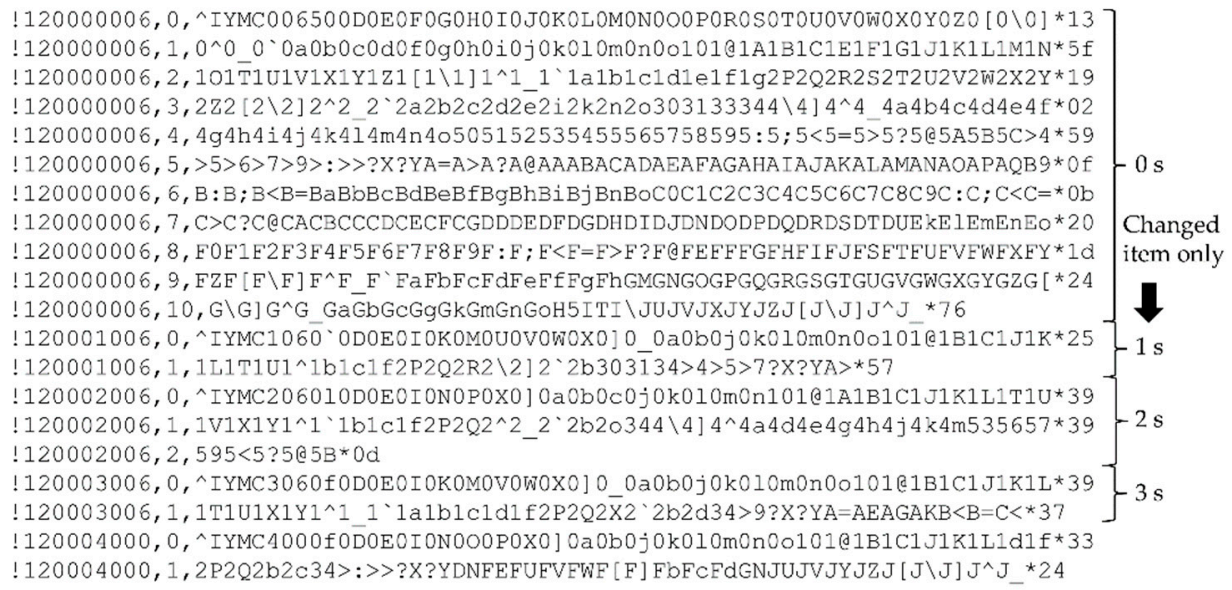

Figure 15. Example of the shipboard data encoded using the proposed six-bit differential binary encoding method.

Table 4. Shipboard data size and required transmission rate obtained by using the original NMEA sentence data format and by applying the proposed data compression method based on the six-bit differential binary encoding.

\begin{tabular}{|c|c|c|c|c|c|}
\hline \multirow[b]{2}{*}{ Day } & \multicolumn{2}{|c|}{ NMEA (ASCII Text) } & \multicolumn{3}{|c|}{ Differential Binary } \\
\hline & $\begin{array}{c}\text { Size } \\
\text { (bytes) }\end{array}$ & $\begin{array}{c}\text { Transmission } \\
\text { Rate (bps) }\end{array}$ & $\begin{array}{c}\text { Size } \\
\text { (bytes) }\end{array}$ & $\begin{array}{c}\text { Transmission } \\
\text { Rate (bps) }\end{array}$ & $\begin{array}{l}\text { Percentage of } \\
\text { Original Rate }\end{array}$ \\
\hline 1 & 420075869 & 38896 & 12834787 & 1188 & $3.1 \%$ \\
\hline 2 & 383417540 & 35502 & 14322600 & 1326 & $3.7 \%$ \\
\hline 3 & 378660939 & 35061 & 12747110 & 1180 & $3.4 \%$ \\
\hline 4 & 333396756 & 30870 & 10005819 & 926 & $3.0 \%$ \\
\hline 5 & 373968226 & 34627 & 13126548 & 1215 & $3.5 \%$ \\
\hline 6 & 379365849 & 35126 & 12729161 & 1179 & $3.4 \%$ \\
\hline 7 & 374306715 & 34658 & 14455567 & 1338 & $3.9 \%$ \\
\hline 8 & 417087087 & 38619 & 13881659 & 1285 & $3.3 \%$ \\
\hline 9 & 381812092 & 35353 & 13959130 & 1293 & $3.7 \%$ \\
\hline 10 & 387986049 & 35925 & 14175340 & 1313 & $3.7 \%$ \\
\hline 11 & 388698134 & 35991 & 10983768 & 1017 & $2.8 \%$ \\
\hline 12 & 405285135 & 37526 & 12475967 & 1155 & $3.1 \%$ \\
\hline 13 & 496322151 & 45956 & 16696313 & 1546 & $3.4 \%$ \\
\hline 14 & 497851142 & 46097 & 16887465 & 1564 & $3.4 \%$ \\
\hline 15 & 467942678 & 43328 & 11513411 & 1066 & $2.5 \%$ \\
\hline 16 & 317855596 & 29431 & 12988511 & 1203 & $4.1 \%$ \\
\hline 17 & 319283225 & 29563 & 12574645 & 1164 & $3.9 \%$ \\
\hline 18 & 309706452 & 28677 & 11375970 & 1053 & $3.7 \%$ \\
\hline 19 & 305818152 & 28316 & 10162442 & 941 & $3.3 \%$ \\
\hline 20 & 316926862 & 29345 & 12747204 & 1180 & $4.0 \%$ \\
\hline 21 & 316142108 & 29272 & 12950912 & 1199 & $4.1 \%$ \\
\hline 22 & 305996268 & 28333 & 11413855 & 1057 & $3.7 \%$ \\
\hline Total & 8277905025 & & 285008184 & & \\
\hline Average & 376268410 & 34840 & 12954917 & 1200 & $3.4 \%$ \\
\hline St. dev. & 57362724 & 5311 & 1716563 & 159 & $0.4 \%$ \\
\hline
\end{tabular}

In addition, Table 4 shows the values of data size and transmission rates obtained by using the proposed data compression method based on the six-bit differential binary encoding technique. The total data size reaches 285008184 bytes using this encoding technique, with an average of 12954917 bytes per day and a standard deviation of 1716563 bytes. The average transmission rate required is $1200 \mathrm{bps}$, which is $3.4 \%$ of the transmission rate required to transmit data in the original format. Therefore, the proposed data encoding method reduces the average transmission rate required by 29 times. 
The standard deviation of the transmission rates for this method is $159 \mathrm{bps}(0.4 \%)$. The maximum absolute value of the required transmission rate was recorded on day 14 and was 1564 bps (3.4\%), whereas the minimum value, recorded on day 4, was 926 bps (3.0\%). Regarding the relative percentage values of the required transmission rate, the maximum value of $4.1 \%$ (1 $199 \mathrm{bps}$ ) was recorded on day 21 , while the recorded data shows the minimum value of $2.5 \%$ (1 066 bps) occurred on day 15 .

Table 5 provides the quantitative comparison of the proposed variable-record-length six-bit differential binary encoding method with several other data conversion methods of similar complexity, considering both fixed-record-length and variable-record-length methods. The tested methods include data encoding using Comma Separated Values (CSV) text with tags indicating the data items, encoding based on fixed-length simple CSV text for all data items, fixed-length binary encoding, and variable-record-length method based on differential data encoding in the form of text values with tags.

Table 5. Required transmission rates achieved by the tested shipboard data conversion methods and the corresponding compression times. The transmission rates are given as percentages of the transmission rate required to transmit data in the original NMEA sentence format. The required computation times are given in seconds.

\begin{tabular}{cccccc}
\hline & $\begin{array}{c}\text { CSV Text } \\
\text { with Tags }\end{array}$ & $\begin{array}{c}\text { Fixed-Length } \\
\text { CSV Text }\end{array}$ & $\begin{array}{c}\text { Fixed-Length } \\
\text { Binary }\end{array}$ & $\begin{array}{c}\text { Differential } \\
\text { CSV Text }\end{array}$ & $\begin{array}{c}\text { Differential } \\
\text { Binary }\end{array}$ \\
\hline Average & $73.0 \%$ & $39.4 \%$ & $36.7 \%$ & $12.8 \%$ & $3.4 \%$ \\
St. dev. & $7.5 \%$ & $4.4 \%$ & $5.4 \%$ & $1.6 \%$ & $0.4 \%$ \\
Comp. time & $0.001324 \mathrm{~s}$ & $0.001320 \mathrm{~s}$ & $0.000379 \mathrm{~s}$ & $0.000537 \mathrm{~s}$ & $0.000253 \mathrm{~s}$ \\
\hline
\end{tabular}

The comparison is made based on the data transmission rates required after the application of each method to the actual shipboard data, thus providing information on its conversion efficiency. The transmission rates are expressed as percentages of the transmission rate required to transmit data in the original NMEA sentence format. The results presented in Table 5 show that the proposed encoding method outperforms other techniques tested. More precisely, it surpasses the conversion efficiency of the encoding using CSV text with tags by $69.6 \%$, the fixed-length CSV text encoding by $36.0 \%$, the fixed-length binary encoding by $33.3 \%$, and the differential CSV text encoding by $9.4 \%$.

In addition, the required computation time of the compression procedure is shown in Table 5 for each tested algorithm. These values represent the average processing times required to compress the data corresponding to one second to be transmitted, and the processing time value is shown in seconds. The computation times were obtained as a result of processing by a $C$ language program in a Windows 10 OS environment on a PC equipped with an Intel ${ }^{\circledR}$ Core $^{\mathrm{TM}}$ i7 Processor. Using the proposed algorithm, the data required to be transmitted in one second is compressed in $0.000253 \mathrm{~s}$. Therefore, it can be said that the computation time for the compression using the proposed method is almost negligible. Moreover, as seen in Table 5, the computation time required by the proposed data compression algorithm is significantly lower than those required by the other tested methods.

Figure 16 shows the visual comparison of the tested onboard data encoding methods regarding the required transmission rates during the 22 days considered. The transmission rates are given as percentages of the reference transmission rate required to transmit data in the original format. As seen in Figure 16, the proposed method provides stable performance throughout the observed period, with a conversion efficiency superior to the other tested methods.

It is assumed that the compressed data will be transmitted using, for example, the data line of Inmarsat satellite communication. As shown in Table 4, as a result of compression, the speed required for data communication is about $1 \mathrm{kbps}$, and it can be said that it is realistic to use a data line of satellite communication. The experimental results shown in Table 5 and Figure 15 are averaged using the data acquired in various situations, and it is unlikely that the compression ratio will change significantly depending on the nature of 
the data. Therefore, the proposed encoding algorithm should always be selected, and it can be said that the reliability of communication depends on the communication line used.

The data used was obtained sailing in the western part of Japan and near Kyushu Island. The ship's route is shown in Figure 17.

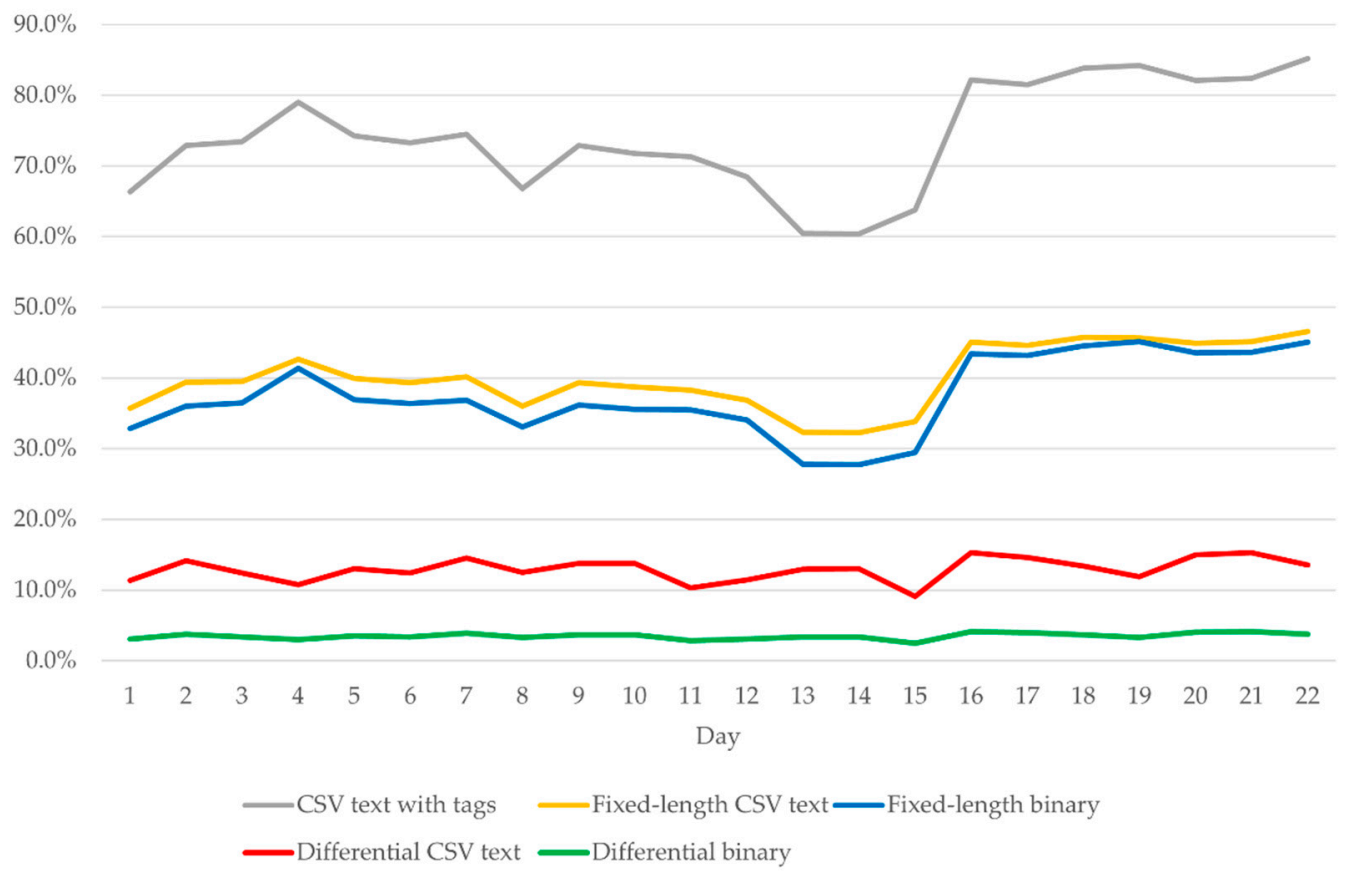

Figure 16. Comparison of the shipboard data conversion methods in terms of the required transmission rates relative to that required to transmit data in the original NMEA sentence format.

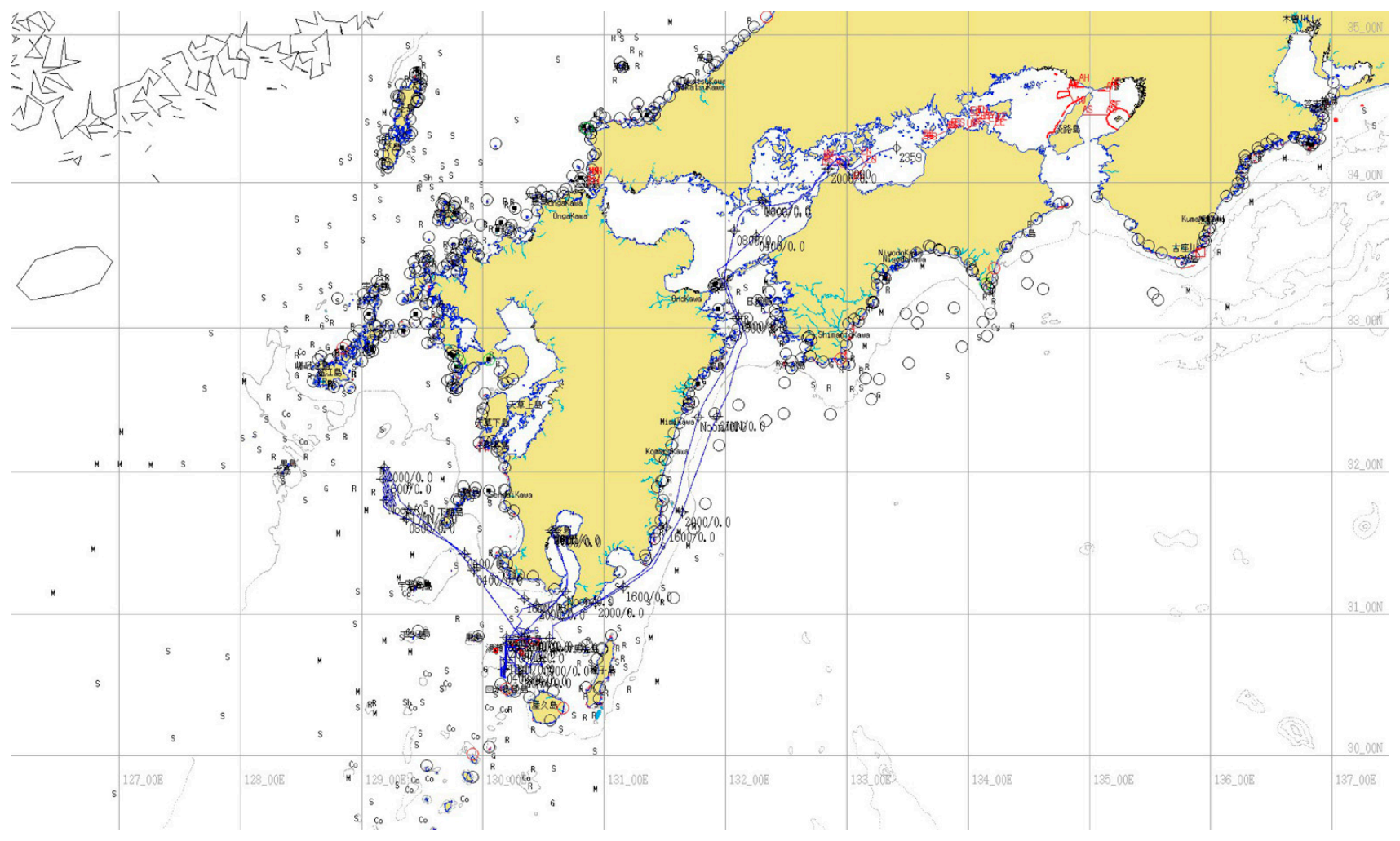

Figure 17. Route of TS Fukae Maru during the data acquisition. 


\section{Conclusions}

Current trends in the maritime transport sector include the digitalization of ships and the development of sustainable autonomous shipping. These concepts require continuous real-time transmission of large amounts of digital shipboard data, which may be hampered by current communications limitations, including low speeds, limited capacity, and high costs. As a result, further upgrades and modernization of the maritime communications network may be needed, representing a significant effort in terms of required financial cost, material resources, and widespread application. An alternative approach to improving maritime communications capacity may involve the application of specialized data compression methods. The adaptive compression approach proposed in this study has been shown to efficiently reduce the size of transmitted shipboard data to an average of $3.4 \%$ of the originally sent data. Moreover, the presented approach provides a significant performance improvement over the several competing data conversion techniques. Therefore, this straightforward data compression method can be quickly and efficiently implemented in the ship communication system to enable future remote voyage monitoring and control functions.

Author Contributions: Conceptualization, I.J., N.L. and N.W.; methodology, N.W.; software, N.W.; validation, N.W.; formal analysis, I.J., N.L., N.W. and H.L.; investigation, N.W.; resources, I.J., N.L. and N.W.; data curation, N.L. and N.W.; writing-original draft preparation, N.L. and N.W.; writingreview and editing, I.J., N.L., N.W. and H.L.; visualization, N.L. and N.W.; supervision, I.J. and N.W.; project administration, I.J. and N.W.; funding acquisition, I.J. and N.W. All authors have read and agreed to the published version of the manuscript.

Funding: This research was supported by the European Regional Development Fund within the Interreg V-A, Italy - Croatia, under the project MarItime and MultimOdal Sustainable pAssenger transport solutions and services-MIMOSA (Application ID-10249002) and by the University of Rijeka, Faculty of Maritime Studies, under the project "Development of advanced digital signal processing algorithms with application in the maritime sector".

Data Availability Statement: Not applicable.

Conflicts of Interest: The authors declare no conflict of interest.

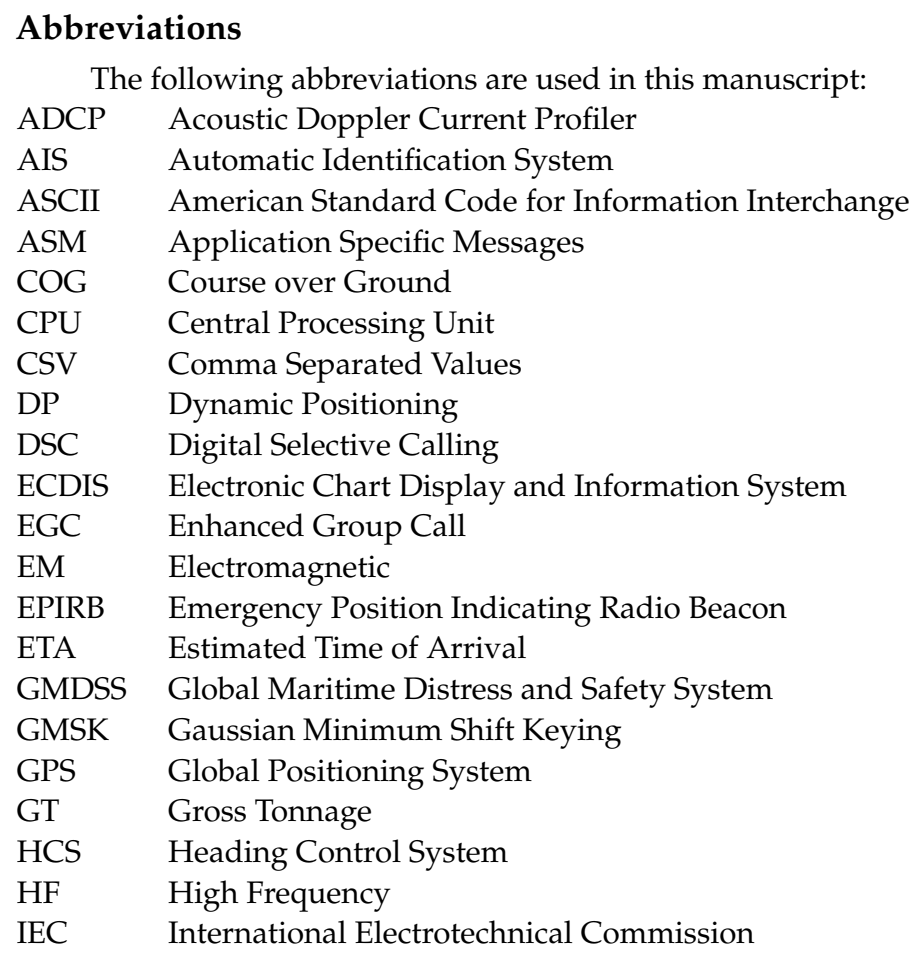




$\begin{array}{ll}\text { IMO } & \text { International Maritime Organization } \\ \text { ITU } & \text { International Telecommunication Union } \\ \text { LAN } & \text { Local Area Network } \\ \text { LEO } & \text { Low Earth Orbit } \\ \text { MF } & \text { Medium Frequency } \\ \text { MMSI } & \text { Maritime Mobile Service Identity } \\ \text { NBDP } & \text { Narrow Band Direct Printing } \\ \text { NMEA } & \text { National Marine Electronics Association } \\ \text { RAIM } & \text { Receiver Autonomous Integrity Monitoring } \\ \text { RCC } & \text { Rescue Coordination Center } \\ \text { SAR } & \text { Search and Rescue } \\ \text { SOG } & \text { Speed over Ground } \\ \text { SOLAS } & \text { International Convention for Safety of Life at Sea } \\ \text { TCS } & \text { Track Control System } \\ \text { TS } & \text { Training Ship } \\ \text { UTC } & \text { Coordinated Universal Time } \\ \text { VDE } & \text { VHF Data Exchange } \\ \text { VDES } & \text { VHF Data Exchange System } \\ \text { VDR } & \text { Voyage Data Recorder } \\ \text { VHF } & \text { Very High Frequency } \\ \text { VTS } & \text { Vessel Traffic Service }\end{array}$

\section{References}

1. Wozniak, J.; Gierlowski, K.; Hoeft, M. Broadband communication solutions for maritime ITSs: Wider and faster deployment of new e-navigation services. In Proceedings of the 2017 15th International Conference on ITS Telecommunications (ITST), Warsaw, Poland, 29-31 May 2017; pp. 1-11.

2. Wang, J.; Zhou, H.; Li, Y.; Sun, Q.; Wu, Y.; Jin, S.; Quek, T.Q.S.; Xu, C. Wireless channel models for maritime communications. IEEE Access 2018, 6, 68070-68088. [CrossRef]

3. Habib, A.; Moh, S. Wireless channel models for over-the-sea communication: A comparative study. Appl. Sci. 2019, 9, 443. [CrossRef]

4. Xia, T.; Wang, M.M.; Zhang, J.; Wang, L. Maritime internet of things: Challenges and solutions. IEEE Wirel. Commun. 2020, 27, 188-196. [CrossRef]

5. Jiang, Y.; Zheng, Y.; Wang, J. A Novel random access algorithm for very high frequency data exchange (VDE). J. Mar. Sci. Eng. 2020, 8, 83. [CrossRef]

6. Wei, T.; Feng, W.; Chen, Y.; Wang, C.-X.; Ge, N.; Lu, J. Hybrid Satellite-terrestrial communication networks for the maritime internet of things: Key technologies, opportunities, and challenges. IEEE Internet Things J. 2021, 8, 8910-8934. [CrossRef]

7. ShipRight Design and Construction. Digital Ships_Procedure for Assignment of Digital Descriptive Notes for Autonomous and Remote Access Ships; Lloyd's Register: London, UK, 2019.

8. Sanchez-Gonzalez, P.-L.; Díaz-Gutiérrez, D.; Leo, T.J.; Núñez-Rivas, L.R. Toward Digitalization of maritime transport? Sensors 2019, 19, 926. [CrossRef]

9. Baldauf, M.; Kitada, M.; Mehdi, R.; Dalaklis, D. E-Navigation, digitalization and unmanned ships: Challenges for future maritime education and training. In Proceedings of the 12th International Technology, Education and Development Conference (INTED), Valencia, Spain, 5-7 March 2018.

10. International Maritime Organization (IMO) Autonomous Shipping. Available online: https://www.imo.org/en/MediaCentre/ HotTopics/Pages/Autonomous-shipping.aspx (accessed on 12 June 2021).

11. Levander, O. Autonomous ships on the high seas. IEEE Spectr. 2017, 54, 26-31. [CrossRef]

12. Ahvenjärvi, S. The Human element and autonomous ships. TransNav. Int. J. Mar. Navig. Saf. Sea Transp. 2016, 10, 517-521. [CrossRef]

13. Munim, Z.H. Autonomous ships: A review, innovative applications and future maritime business models. Supply Chain Forum Int. J. 2019, 20, 266-279. [CrossRef]

14. Felski, A.; Zwolak, K. The ocean-going autonomous ship-Challenges and threats. J. Mar. Sci. Eng. 2020, 8, 41. [CrossRef]

15. Im, I.; Shin, D.; Jeong, J. Components for smart autonomous ship architecture based on intelligent information technology. Procedia Comput. Sci. 2018, 134, 91-98. [CrossRef]

16. Lopac, N.; Jurdana, I.; Lerga, J.; Wakabayashi, N. Particle-swarm-optimization-enhanced radial-basis-function-kernel-based adaptive filtering applied to maritime data. J. Mar. Sci. Eng. 2021, 9, 439. [CrossRef]

17. Allal, A.A.; Mansouri, K.; Youssfi, M.; Qbadou, M. Toward energy saving and environmental protection by implementation of autonomous ship. In Proceedings of the 2018 19th IEEE Mediterranean Electrotechnical Conference (MELECON), Marrakech, Morocco, 2-7 May 2018; pp. 177-180. 
18. Lee, P.T.-W.; Kwon, O.K.; Ruan, X. Sustainability challenges in maritime transport and logistics industry and its way ahead. Sustainability 2019, 11, 1331. [CrossRef]

19. International Telecommunication Union Radiocommunication Sector (ITU-R). Recommendation ITU-R M.1371-5: Technical Characteristics for an Automatic Identification System Using Time Division Multiple Access in the VHF Maritime Mobile Frequency Band; International Telecommunication Union Radiocommunication Sector (ITU-R): Geneva, Switzerland, 2014.

20. International Maritime Organization (IMO). AIS Transponders. Available online: https://www.imo.org/en/OurWork/Safety/ Pages / AIS.aspx (accessed on 12 June 2021).

21. Lee, E.; Mokashi, A.J.; Moon, S.Y.; Kim, G. The Maturity of automatic identification systems (ais) and its implications for innovation. J. Mar. Sci. Eng. 2019, 7, 287. [CrossRef]

22. Wakabayashi, N.; Jurdana, I. Maritime communications and remote voyage monitoring. In Proceedings of the 2020 International Conference on Broadband Communications for Next Generation Networks and Multimedia Applications (CoBCom), Graz, Austria, 7-9 July 2020; pp. 1-8.

23. Perera, L.P.; Mo, B. Ship performance and navigation data compression and communication under autoencoder system architecture. J. Ocean Eng. Sci. 2018, 3, 133-143. [CrossRef]

24. International Maritime Organization (IMO). International Convention for the Safety of Life at Sea (SOLAS). 1974. Available online: https:/ / www.imo.org/en/About/Conventions/Pages/International-Convention-for-the-Safety-of-Life-at-Sea-(SOLAS) -1974.aspx (accessed on 12 June 2021).

25. International Maritime Organization (IMO). Focus on IMO. Shipping Emergencies—Search and Rescue and the GMDSS; International Maritime Organization (IMO): Lambeth, London, 1999.

26. International Maritime Organization (IMO). COMSAR/Circ.32. Harmonization of GMDSS Requirements for Radio Installations on Board SOLAS Ships; International Maritime Organization (IMO): Lambeth, London, 2004.

27. International Maritime Organization (IMO). International Convention for the Safety of Life at Sea (SOLAS), Chapter IV. Radiocommunications; International Maritime Organization (IMO): Lambeth, London, 1974.

28. International Maritime Organization (IMO). International Convention on Maritime Search and Rescue (SAR). Available online: https:/ / www.imo.org/en/About/Conventions/Pages/International-Convention-on-Maritime-Search-and-Rescue-(SAR) .aspx (accessed on 12 June 2021).

29. Inmarsat Maritime, Inmarsat Corporate Website. Available online: https://www.inmarsat.com/en/solutions-services/maritime. html (accessed on 12 June 2021).

30. Inmarsat Solutions \& Services, Inmarsat Corporate Website. Available online: https://www.inmarsat.com/en/solutions-services html (accessed on 12 June 2021).

31. Lázaro, F.; Raulefs, R.; Wang, W.; Clazzer, F.; Plass, S. VHF Data Exchange System (VDES): An enabling technology for maritime communications. CEAS Space J. 2019, 11, 55-63. [CrossRef]

32. International Maritime Organization (IMO). International Convention for the Safety of Life at Sea (SOLAS), Chapter V. Safety of Navigation; International Maritime Organization (IMO): Lambeth, London, 2002.

33. Pallotta, G.; Vespe, M.; Bryan, K. Vessel pattern knowledge discovery from AIS data: A framework for anomaly detection and route prediction. Entropy 2013, 15, 2218-2245. [CrossRef]

34. Liu, J.; Shi, G.; Zhu, K. Vessel Trajectory prediction model based on AIS sensor data and adaptive chaos differential evolution support vector regression (ACDE-SVR). Appl. Sci. 2019, 9, 2983. [CrossRef]

35. Jiang, Y.; Zheng, K. The single-shore-station-based position estimation method of an automatic identification system. Sensors 2020, 20, 1590. [CrossRef]

36. Bakdi, A.; Glad, I.K.; Vanem, E.; Engelhardtsen, Ø. AIS-based multiple vessel collision and grounding risk identification based on adaptive safety domain. J. Mar. Sci. Eng. 2020, 8, 5. [CrossRef]

37. Chao, H.-C.; Wu, H.-T.; Tseng, F.-H. AIS meets IoT: A network security mechanism of sustainable marine resource based on edge computing. Sustainability 2021, 13, 3048. [CrossRef]

38. International Electrotechnical Commission (IEC). IEC 61162-1 Maritime Navigation and Radiocommunication Equipment and Systems_Digital Interfaces_Part. 1: Single Talker and Multiple Listeners; International Electrotechnical Commission (IEC): Geneva, Switzerland, 2010.

39. Watanabe, T.; Wakabayashi, N.; Urakami, M.; Terada, D. Development of track control system utilizing heading control system for ocean observation sailing. In Proceedings of the 27th International Ocean and Polar Engineering Conference, International Society of Offshore and Polar Engineers (ISOPE), San Francisco, CA, USA, 25-30 June 2017; pp. 529-536.

40. Wakabayashi, N.; Watanabe, T.; Urakami, M.; Terada, D. Development of simple dynamic positioning system-Algorithm and user interface. In Proceedings of the 27th International Ocean and Polar Engineering Conference, International Society of Offshore and Polar Engineers (ISOPE). San Francisco, CA, USA, 25-30 June 2017; pp. 507-512.

41. Wakabayashi, N.; Watanabe, T.; Urakami, M.; Yano, Y. Tablet control system for offshore support and research vesseldevelopment, implementation, and operational testing. In Proceedings of the 28th International Ocean and Polar Engineering Conference, International Society of Offshore and Polar Engineers (ISOPE), Sapporo, Japan, 10-15 June 2018; pp. 922-928.

42. Wakabayashi, N.; Yano, Y.; Shiotani, S.; Murai, K. Sailing data transfer and display system using wireless LAN in the bridge and its application to navigation support system. In Proceedings of the 11th IAIN (International Association of Institutes of Navigation) World Congress, Berlin, Germany, 21-24 October 2003; Volume 160, pp. 42-46. 
43. Fujii, M.; Hayashi, M.; Urakami, M.; Wakabayashi, N. The development of meteorological and oceanographic data collection and recording system operating on training ship. In Proceedings of the ASME 2014 33rd International Conference on Ocean, Offshore and Arctic Engineering, San Francisco, CA, USA, 8-13 June 2014; Volume 8B, p. V08BT06A007.

44. Wakabayashi, N.; Watanabe, T.; Urakami, M.; Yano, Y. Motor vessel LAN-Design, implementation, and operation. In Proceedings of the 2018 International Conference on Broadband Communications for Next Generation Networks and Multimedia Applications (CoBCom), Graz, Austria, 11-13 July 2018; pp. 1-8.

45. National Marine Electronics Association (NMEA). NMEA 0183 Standard for Interfacing Marine Electronic Devices Version 3.01; National Marine Electronics Association (NMEA): Severna Park, MD, USA, 2002. 